INTERPRETATION AND ENFORCEMENT OF CANADA'S 161 ORDER

\title{
To Breach or Not to Breach: Exploring Inconsistencies in the Interpretation and Enforcement of Canada's Section 161 Order for Sexual Offending
}

\author{
Natasha Knack $^{a, b^{*}}$, Julie Blais ${ }^{c}, \&$ J. Paul Fedoroff ${ }^{b, d}$
}

${ }^{a}$ Department of Psychology, Carleton University, Ottawa, Canada; ${ }^{b}$ Forensic Research Unit, The Royal's Institute of Mental Health Research, Ottawa, Canada; 'Department of Psychology and Neuroscience, Dalhousie University, Halifax, Canada; ${ }^{d}$ Department of Psychiatry, University of Ottawa, Ottawa, Canada.

Published in Canadian Journal of Criminology and Criminal Justice

\section{*Corresponding author}

Email: Natasha.Knack@ carleton.ca

Acknowledgements: We are grateful to those who participated in our study for their time and willingness to share their opinions. All opinions, findings, conclusions, or recommendations expressed herein are those of the authors. 
INTERPRETATION AND ENFORCEMENT OF CANADA'S 161 ORDER

\begin{abstract}
Community-based risk management strategies for people convicted of sexual offences (PCSO) can hinder successful reintegration, which plays an important role in reducing sexual recidivism. Section 161 of the Criminal Code is a Canadian risk management strategy, which aims to protect children by prohibiting people convicted of sexual offences against children (PCSO-C) from engaging in behaviours assumed (sometimes erroneously) to be associated with sexual offending. This study was the first to evaluate Section 161 prohibition orders, and explored inconsistencies in the interpretation and enforcement of these conditions between PCSO-C subject to Section 161 and two non-forensic subsamples of the Canadian public community members and undergraduate students. Non-forensic participants expressed more negative attitudes toward the treatment of PCSO, which were found to mediate the relationship between group membership and subjective legal decision-making. Degree of support for Section 161 conditions did not appear to moderate this effect. Results raise concerns about the potential for increased personal discretion when enforcing or adhering to ambiguous or overly broad legal conditions. We suggest the need for continued efforts to establish an empirical understanding of the application, efficacy, and potential collateral consequences associated with this Canadian risk management strategy.
\end{abstract}


INTERPRETATION AND ENFORCEMENT OF CANADA'S 161 ORDER

\section{To Breach or Not to Breach: Exploring Inconsistencies in the Interpretation and Enforcement of Canada's Section 161 Order for Sexual Offending}

Current legislation for people convicted of sexual offences (PCSO) aims to prevent sexual recidivism by means of restrictive and sometimes punitive community-based risk management strategies (e.g., sex offender registration), which some researchers have argued is a reflection of the fear and disgust commonly associated with PCSO (Budd \& Mancini 2016; Lynch 2002). Research indicates that existing risk management strategies are often ineffective and can actually increase the risk of recidivism (Appelbaum 2008; Levenson 2018) due to possible collateral consequences, including difficulty obtaining housing, employment, and social supports (Call 2018; Cubellis, Walfield, \& Harris 2018). The inability to satisfy these basic human needs has been negatively associated with community reintegration, which is often found to play an important role in preventing sexual reoffending (Lussier \& Gress 2014; Willis \& Grace 2009).

One risk management strategy unique to Canada is s. 161 of the Criminal Code, RSC 1985, c C-46 (herein referred to as a 161 order), which can be part of a judicial sentence given to people convicted of sexual offences against children (PCSO-C $\mathrm{C}^{1}$, including child pornography offences. A 161 order can be imposed for any length of time, including life, and prohibits behaviours involving communication with and proximity to people under age 16 , as well as Internet use (see Appendix A for a copy of s. 161). While there has yet to be any empirical research on 161 orders, multiple legal cases have demonstrated that some conditions can be overly vague (see $R$ v Lachapelle, 2008 BJC 728; $R$ v Perron, 2010 ONCA 498). Moreover, 161

\footnotetext{
${ }^{1}$ Since many of the risk management strategies we discuss apply to people convicted of any type of sexual offence, we use PCSO when referring to this population more generally, and PCSO-C when referring specifically to people convicted of at least one sexual offence against a child (including child pornography offences).
} 
INTERPRETATION AND ENFORCEMENT OF CANADA'S 161 ORDER

orders use complex language and have a reading level of 19.4 (i.e., college graduate or above) based on the Flesch-Kincaid readability test. These factors can leave people who are subject to a 161 order unsure of exactly what behaviours are prohibited (while parole/probation officers will ideally try to mitigate any confusion, they cannot always be certain of how these conditions will be enforced by individual police officers). Based on concerns regarding the potential ambiguity of s. 161 , this study explored the interpretation and enforcement of 161 orders from the perspective of both the Canadian public and PCSO-C subject to these prohibitions.

\section{Community-Based Risk Management Strategies for PCSO}

Past research has found that approximately $95 \%$ of PCSO have no history of sexual offences (Craun, Simmons, \& Reeves 2011; Sandler, Freeman, \& Socia 2008), and rates of sexual recidivism are consistently reported to be between $5 \%$ to $15 \%$ in the first five years, further decreasing over time (Hanson, Harris, Helmus, \& Thornton 2014; Hanson, Harris, Letourneau, Helmus, \& Thornton 2018). Despite this, current risk management strategies are based on inaccurate (over)estimations regarding the risk of sexual re-offending (McAlinden 2007), and typically focus on preventing recidivism through "tough on crime" approaches rather than high-quality reintegration planning and support (Fortune, Ward, \& Willis 2012). This has resulted in the implementation of risk management strategies that do little more than provide the public with a false sense of security, leading to what Budd and Mancini (2016: 362) call "an era of crime control theatre".

To date, research on community-based risk management strategies has focused primarily on sex offender registration, public notifications, and residency restrictions, with much of this work emanating from the United States. In short, studies have consistently failed to find empirical support for the efficacy of these strategies (see Ackerman, Levenson, \& Harris 2012; 
INTERPRETATION AND ENFORCEMENT OF CANADA'S 161 ORDER

Sandler et al. 2008; Vásquez, Maddan, \& Walker 2008; Zandbergen, Levenson, \& Hart 2010;

Zgoba \& Bachar 2009). Sex offender registration and public notifications are also used in

Canada, but with notable differences in their implementation (e.g., private rather than public

registries; Murphy, Fedoroff, \& Martineau 2009). In addition to 161 orders, other risk

management strategies specific to Canada include the Dangerous Offender and Long-Term

Offender designations (s. 753 and s. 753.1, respectively), which allow for longer periods of incarceration and community supervision, and s. 810 recognizance orders, which allow for community supervision of people considered at risk of committing a sexual or serious personal injury offence (s. 810.1 and s. 810.2, respectively; Criminal Code, RSC 1985, c C-46).

As previous authors have provided excellent reviews of the risk management strategies used in Canada and the United States, including their legislative history (see Corăbian 2016; Humphrey \& Van Brunschot 2015; Petrunik 2002; 2003; Petrunik, Murphy, \& Fedoroff 2008), we have not described these strategies in detail here. It is worth noting, however, that despite the thoroughness of these reviews, none of them include s. 161. A brief mention of 161 orders was made by Murphy and Fedoroff (2013), who explored Canadian registrants' perceptions of sex offender registration and found that, while the majority did not consider registration to be particularly onerous or associated with negative outcomes, some described frustrations resulting from conditions on their 161 order.

Empirical research on Canadian risk management strategies is generally lacking (Petrunik et al. 2008), although the 810.1 and 810.2 recognizance orders provide one exception. Past research has included descriptive profiles of Canadians subject to these recognizance orders, as well as longitudinal studies exploring dynamic factors, community reintegration, and desistance among this population (Humphrey \& Van Brunschot 2018; Lussier, Deslauriers-Varin, \& Râtel 
INTERPRETATION AND ENFORCEMENT OF CANADA'S 161 ORDER

2010; Lussier \& Gress 2014; Lussier \& McCuish 2016). All but one of the 161 order conditions (i.e., prohibiting working/volunteering with people under 16) can also be included in an 810.1 order; unlike s. 161, however, s. 810 does not appear to include a standard set of conditions. Rather, conditions are determined on a case-by-case basis, in response to the individual's offence patterns (Lussier \& Gress 2014; MacAulay 2001). While the maximum length for an 810.1 or 810.2 order is two years, s. 161 can be given for life (Criminal Code, RSC 1985, c C-46).

\section{Attitudes toward PCSO and Support for Community-Based Risk Management Strategies}

Attitudes toward PCSO have been found to differ between students, health and correctional professionals, and the general public. This is relevant as these attitudes likely have the potential to influence support for community risk management strategies and perceptions of their efficacy. Furthermore, public attitudes and opinions have generally been shown to influence the adoption of different government policies in both the United States (Hartley \& Russett 1992; Sharpe 1999; Wlezien 2004) and Canada (Soroka \& Wlezien 2004; 2010). Much of the research on attitudes toward PCSO originates from the United States (see Challinor \& Duff 2019; Flynt 2016; Hogue 1993; Harris, Lobanov-Rostovsky, \& Levenson 2015; Johnson, Hughes, \& Ireland 2007; Levenson, Brannon, Fortney, \& Baker 2007; Mustaine, Tewksbury, Connor, \& Payne 2015; Nelson, Herlihy, \& Oescher 2002; Tewksbury \& Mustaine 2013), and thus may not accurately reflect the attitudes held by Canadians. In fact, a recent study of undergraduate students and community members from both countries found that, compared to Americans, Canadians held more traditional (and potentially stereotypical) views of PCSO, perceiving them as predatory and "unwilling or unable to control their sexual behaviour"; the latter belief was stronger among community members (Jung, Allison, \& Martin 2018: 110). 
INTERPRETATION AND ENFORCEMENT OF CANADA'S 161 ORDER

Jung et al. (2018) suggest that these differences may relate to the finding that Canadians watch more crime-related television shows (e.g., Law \& Order, CSI) than Americans, possibly increasing their exposure to stereotypical portrayals of PCSO (Allison, Sweeney, \& Jung 2013).

This may also help to explain why previous studies have found that Canadians greatly overestimate recidivism rates for PCSO (Corăbian 2016; Olver \& Barlow 2010). Corăbian and Hogan (2012) sampled Canadian undergraduate students, PCSO, and professionals working with PCSO and found that, regardless of participants' own attitudes toward PCSO, the majority agreed that media portrayals of PCSO were negative, promoted stereotypical views, and could contribute to collateral consequences (e.g., difficulties obtaining basic needs, feelings of isolation and stress). For a more thorough discussion of the media's role in shaping Canadians' perceptions about criminal behaviour, see Dowler (2004; 2006) and Tamang (2009).

Studies exploring Canadians' attitudes toward PCSO suggest that in both undergraduate and community samples, more negative attitudes are associated with greater support for policies related to incapacitation/control, whereas more positive attitudes are associated with greater support for policies related to rehabilitation and reintegration (Corăbian 2016; Jung et al. 2018). Olver and Barlow (2010) found that estimated rates of sexual recidivism were higher among female compared to male undergraduate students, and those with no religious affiliation were slightly more supportive of rehabilitation policies for PCSO than those with a religious affiliation. Moreover, openness and agreeableness were found to be predictive of positive attitudes towards rehabilitation, whereas extraversion predicted negative attitudes toward the systems that manage PCSO. Among community members, Corăbian (2016) found that, even after accounting for participants' attitudes toward PCSO, greater support for punitive policies 
INTERPRETATION AND ENFORCEMENT OF CANADA'S 161 ORDER

was associated with female gender, lower levels of education, conservative political views, identifying as non-White, and having children.

\section{Canada's Section 161 Order}

Section 161 aims to protect children from sexual abuse by prohibiting PCSO-C (living in the community) from engaging in the following behaviours, which are assumed to increase the risk of sexual offending: (a) attending public parks or swimming areas where children under age 16 are reasonably expected to be present, as well as daycare centres, schools, playgrounds, and community centres; (a.1) being within a specified distance of the victim's home or other places specified in the order; (b) working or volunteering in a position of power over children; (c) communicating in any way with someone under age 16; and (d) using the Internet or other digital networks (Criminal Code, RSC 1985, c C-46).

Section 161 was introduced as a means of addressing the vague language used in a nowrepealed law that prohibited PCSO from "loitering in or near a school ground, playground, public park or bathing area" (i.e., s. 179(1)(b); see $R v$ Heywood, 1992 BCCA 6008; $R$ v Heywood, 1994 3 SCR 761). However, multiple appeals and Supreme Court cases regarding inconsistencies in the interpretation and enforcement of the s. 161 conditions demonstrate that issues related to the ambiguity of this order are ongoing. This is particularly true for Condition (a), which most closely reflects s. 179(1)(b). For example, Courts have disagreed on whether the defining characteristic of a public park or playground is its physical/geographical features $(R v$

Lachapelle, 2008 BCJ 728) or the nature of ongoing activities ( $R$ v Perron, 2009 ONCA 498); this definitional issue is further discussed by Hutchinson (2010).

These cases highlight that even judicial officials trained to interpret Canadian law at the highest level do not necessarily agree on the correct interpretation of the 161 order prohibitions. 
INTERPRETATION AND ENFORCEMENT OF CANADA'S 161 ORDER

The Court in $R$ v McIntosh, 19951 SCR 686 ruled that in cases where legal terminology is ambiguous, judicial interpretation must favour the accused (for a relevant example, see $R v$ Allaby, 2017 SKCA 25). Furthermore, Canada's void for vagueness doctrine (Charter of Rights and Freedoms, s. 7) states that, "In a criminal context, a statutory provision must afford citizens fair notice of the consequences of their conduct and it must limit the discretion of those charged with its enforcement. A provision that fails to satisfy these essential requirements is void for vagueness" ( $R$ v Levkovic, 2013 SCC 25 at para 1$).$

\section{Current Study}

Considering the inconsistent judicial interpretations of 161 orders, along with past research indicating that PCSO may have difficulty understanding the legal conditions associated with other risk management strategies (Levenson, D’Amora, \& Hern 2007; Powell, Day, Benson, Vess, \& Graffam 2014), the goal of our study was to explore possible inconsistencies in the interpretation and enforcement of 161 order conditions. Based on what is known about attitudes toward PCSO and support for community-based risk management strategies, and the fact that public opinions about management strategies have the potential to influence government policies (Soroka \& Wlezien 2004), we also explored whether differences in legal decisionmaking were related to group membership, attitudes toward the treatment of PCSO, or support for the 161 order.

The study included one forensic sample comprised of outpatient PCSO-C subject to a 161 order, and two non-forensic comparison groups, including members of the general public (GP) and undergraduate students (UG). Participants were asked to use an exact copy of s. 161 to determine if multiple scenarios could and/or should constitute a breach. The question of whether a scenario could constitute a breach relates more to the "letter of the law", whereas deciding if a 
INTERPRETATION AND ENFORCEMENT OF CANADA'S 161 ORDER

scenario should constitute a breach involves participants' personal opinions regarding the appropriate application of 161 orders. These variables were intended to represent objective and subjective legal decision-making, respectively. The hypotheses, methodology, and analysis plan were pre-registered on the Open Science Framework prior to data collection and can be accessed here: https://osf.io/b8d6k/?view_only=b5901663a30b4b15a1527fbcbc949a51

\section{Hypotheses}

Hypothesis 1 (H1): Since all scenarios could technically violate a 161 order, we did not expect to find significant differences on Could Breach scores between the forensic (i.e., PCSOC) and non-forensic groups (i.e., GP and UG) (H1a); however, due to the ambiguous terminology used in some conditions, and the increased personal discretion that this ambiguity allows, we did expect to find significant differences on Should Breach scores (H1b).

Hypothesis 2 (H2): We expected that between-group differences on Should Breach scores would be mediated by participants' attitudes toward the treatment of PCSO (H2a), and that the strength of these relationships would be moderated by participants' degree of support for 161 order conditions (H2b).

\section{Methodology}

\section{Participants}

Participants included 175 men and women between age 18 to 74, who could read and understand English, and fell into one of the following groups: (1) PCSO-C currently subject to a 161 order $(n=39)$; (2) members of the Canadian general public (GP; $n=56$ ); and (3) undergraduate students from a Canadian University (UG; $n=80$ ). All participants had at least grade 10 education and had never attended special education classes for learning disabilities; the GP and UG groups included only people who had never been charged with a criminal offence. 
INTERPRETATION AND ENFORCEMENT OF CANADA'S 161 ORDER

Demographic information for these samples is available in Table 1. On average, the PCSO-C group was older $(M=52, S D=12.0$, range $=31-74)$ than both the GP group $(M=34, S D=11.2$, range $=18-62)$ and $\mathrm{UG}$ group $(M=21, S D=6.1$, range $=18-46)$. The PCSO-C group was comprised entirely of Caucasian males, whereas the GP and UG groups had a much higher proportion of females (68\% and $81 \%$, respectively) and showed slightly greater ethnic diversity. Post-secondary education was common in all three samples, although rates were higher in the non-forensic groups. Sixty-nine percent of forensic participants had been convicted of child pornography offences, and $54 \%$ of contact sexual offences against children.

[Table 1 about here]

Regarding the representativeness of our samples, the PCSO-C group was slightly older than the median age of those charged with sexual assault in Canada between 2009 and 2014 $(\mathrm{Med}=49$ vs. 33), and included $100 \%$ compared to $98 \%$ males (Rotenberg 2017). Compared to the Canadian public, our GP sample was slightly younger $(M=34$ vs. 41$)$, had a disproportionately high number of females (Statistics Canada, 2020), was more highly educated, and included fewer participants who had never been married or had children (Statistics Canada 2017). The overall proportion of visible minorities was relatively similar (17.7\% vs. $22.3 \%$ of Canadian population; Statistics Canada 2017), although individual ethnicities were comparatively under- or overrepresented. Unfortunately, population-level demographic information about Canadian undergraduate students is not available for comparison.

While the inclusion of a police sample would have been ideal given that police are responsible for enforcing 161 orders, this was determined to be unfeasible at the time, particularly as the study had not yet shown proof of concept. Thus, we included the GP sample as a non-forensic comparison group in light of the large and established literature demonstrating 
INTERPRETATION AND ENFORCEMENT OF CANADA'S 161 ORDER

the interrelationship between public opinion and policy adoption (e.g., Soroka \& Wlezien 2004). The UG group was included as a second convenient comparison group representing another nonforensic subsection of the Canadian public. We believe these community samples provide valuable insights regarding the potential ambiguity of s. 161, while also offering the first glimpse into how the Canadian public perceives the 161 order conditions.

\section{Participant Screening and Data Preparation}

We used convenience sampling to recruit a total of 492 potential participants, 88 of whom did not meet the study criteria. Of those remaining, 41 did not consent to participate, 86 did not finish the study, and 60 were identified as duplicates; these cases were removed. Among the 217 complete responses, we removed participants who failed the attention $(n=3)$ or fact check $(n=12)$, completed the study in under 25 minutes $(n=11)$, reported giving less than $40 \%$ effort $(n=3)$, or skipped at least $50 \%$ of any study measure $(n=6)$. In the UG group, we removed participants whose status as an undergraduate student was either negative $(n=4)$ or unknown $(n=2)$. Two cases were removed after being identified as influential outliers when using Should Breach scores as an outcome variable (one each from the PCSO-C and UG groups; see pre-registration for more details).

\section{Power Analysis}

Based on several simulations of different types of mediation analysis, Fritz and MacKinnon (2007) recommend that a sample of $N=148$ should be sufficient to detect indirect effects of at least $d=0.26$. Past research exploring between-group differences in attitudes toward the treatment of PCSO has found moderate effect sizes $(d=0.55, d=0.69$; Kjelsberg \& Loos 2008). We proposed recruiting a sample of $N=180$; while our final sample was only $N=175$, it was larger than Fritz and MacKinnon's recommended sample size. Using G*Power 3.1.9.2 
INTERPRETATION AND ENFORCEMENT OF CANADA'S 161 ORDER

(Faul, Erdfelder, Lang, \& Buchner 2007), we determined that with an alpha of .05 and 80\%

power, an effect size of $r=.18$ would be required to detect significant Pearson's correlations in a sample of $N=180$; this increased only slightly $(r=.21)$ for $N=175$.

\section{Recruitment}

The PCSO-C sample was recruited from a Canadian mental health centre, by a research assistant who announced the study at weekly group psychotherapy sessions, and through recruitment advertisements posted within relevant outpatient areas. Interested patients were contacted by phone for screening purposes, and those who met the criteria and wanted to participate were scheduled an appointment. Forensic participants completed the study in-person, and the study did not begin until after they had been fully informed and provided voluntary consent to participate.

The GP group was recruited using online advertisements (i.e., Facebook, Twitter, Kijiji), and the UG group through an advertisement on the University's internal recruitment system. Non-forensic participants were given a link to access and complete the study online using Qualtrics. The link first led to the screening questions, and those who met the criteria were asked to read the consent form and check the appropriate box if they agreed to participate. The consent form briefly explained the nature of 161 orders, including that they are enforced by local police officers, as well as the possible consequences for breaching the conditions. After providing consent, the study began immediately. The PCSO-C and GP groups were given the option of entering a draw for a $\$ 100$ gift card as compensation for participating in the study, and the UG group received a small amount of course credit $(0.5 \%)$. Prior to data collection, the study received ethical approval from the ethics boards at both the mental health hospital and the University. 
INTERPRETATION AND ENFORCEMENT OF CANADA'S 161 ORDER

\section{Measures}

\section{Demographics}

This included 20 items asking about gender, education, parental status, political views, sexual victimization, etc. Forensic participants answered four questions about their offence(s), and non-forensic participants answered four questions about their personal/professional contact with PCSO, and knowledge about treatment for PCSO and sexual offending in general.

\section{Attitudes toward the Treatment of Sex Offenders (ATTSO)}

The ATTSO (Wnuk, Chapman, \& Jeglic 2006) is originally a 35-item measure of attitudes toward the treatment of PCSO, which was later reduced to 15 items found to function well both statistically and theoretically (Cronbach's alpha $=.78, n=170$ ). For this study, we used a revised version with 26 items, including all 15 items selected by the developers. Cronbach's alpha was slightly higher for the 26 items $(\alpha=.90)$ compared to the 15 items $(\alpha=$ .85). This measure used a 5-point Likert scale from "strongly disagree" to "strongly agree". We calculated a mean ATTSO score for each participant, with higher scores representing more negative attitudes towards the treatment of PCSO; this score was used as the mediator in all models. For discussion purposes, this variable is herein referred to as Attitude. We included one question as an instructional manipulation check to assess participants' level of attention; this item was excluded from mean scores.

\section{Support for 161 Order Conditions}

We created this measure to assess participants' degree of support for the specific conditions included in s. 161. Participants used a 6-point Likert scale from "strongly disagree" to "strongly agree" to respond to 10 statements regarding the clarity, practicality, and potential impact of each condition (e.g., "is likely to protect children from sexual abuse", "has the 
INTERPRETATION AND ENFORCEMENT OF CANADA'S 161 ORDER

potential to be misinterpreted"). We included a factual manipulation check at the end of this measure asking participants to describe the purpose of a 161 order. We calculated individual mean scores for each condition, as well as a total mean score that was used as the moderator in the conditional process model; higher scores indicated greater support. For discussion purposes, this variable is herein referred to as Degree of Support.

\section{Order Scenarios}

We created this measure to identify inconsistencies in the interpretation and enforcement of 161 order conditions. It included 10 short scenarios describing situations that could technically constitute a breach of s. 161, some of which were based on true events (see Appendix B for full scenarios). A few details were provided about the fictional subject in the scenarios to reflect information often available to police officers (i.e., basic visual information, criminal history). Participants were first asked to read a verbatim copy of s. 161 (see Appendix A). They were then asked to read each scenario and use the information in s. 161, specifically the five standard conditions, to indicate whether the scenario could constitute a breach (i.e., Could Breach) and/or should constitute a breach (i.e., Should Breach). These five conditions were listed at the bottom of every page for reference. For each participant, we calculated a mean Could Breach and mean Should Breach score (no $=0$ and yes $=1$ ), with higher scores indicating a greater likelihood of reporting the scenarios could and/or should constitute a breach. Mean Could Breach and Should Breach scores were used as outcome variables in all models. 
INTERPRETATION AND ENFORCEMENT OF CANADA'S 161 ORDER

\section{Analysis Plan²}

We used the Hayes (2018) PROCESS macro to conduct mediation and conditional process analyses (see pre-registration for conceptual and statistical models). Since our predictor was categorical, $X$ was represented by $D_{\mathrm{g}-1}$ variables (where $g$ indicates the number of groups), and we selected the forensic group as the reference for the two non-forensic groups. When using a categorical predictor in mediation, the resulting effects must be understood as "relative (direct or indirect) effects", since the observed differences are relative to the reference group, and either unmediated (direct) or mediated (indirect). It is important to note that the terms direct and indirect are strictly intended to refer to mediation effects and should not be interpreted as implying causation. In moderated models, significant effects are described as conditional on the value of the moderator. Hayes (2018: 192) suggests that ' $X$ 's effect on $Y$ can be said to be mediated by $M$ if at least one of the $g-1$ relative indirect effects is different from zero", and $X$ 's effect on $Y$ can be seen as moderated if the size, sign, or strength of the effect is dependent on or can be predicted by $W$.

Hypothesis 1 (H1): We used an unmoderated simple mediation model to test the relative unconditional direct effects of Group $(X)$ on Could Breach $\left(Y_{1}\right)$ and Should Breach $\left(Y_{2}\right)$ scores, independent of the indirect effect of Group on Breach scores through Attitude $(M)$.

Hypothesis 2 (H2): We used the same model from $\mathrm{H} 1$ to test H2a, which involves the relative unconditional indirect effects of Group on Breach scores through Attitude (i.e., mediation). We then added the moderator - Degree of Support ( $W$ ) - to test H2b, which involves

\footnotetext{
${ }^{2}$ We first proposed a moderated serial mediation model with an additional mediator (primary source of information about sex offending). Since PROCESS could not accommodate this categorical mediator, we removed this variable and tested the remaining pathways, the results of which are reported herein (see pre-registration for more details).
} 
INTERPRETATION AND ENFORCEMENT OF CANADA'S 161 ORDER

the relative conditional direct and indirect effects of Group on Breach scores through Attitude conditional on Degree of Support (i.e., moderation).

\section{Preliminary Tests}

Prior to testing the models, we explored the data to determine if the assumptions of OLS regression had been met. While the assumptions of linearity and multicollinearity were met, we found evidence of both heteroscedasticity and non-normality. Since PROCESS computes biascorrected bootstrap 95\% CIs to estimate effects, and provides the option of using a heteroskedasticity-consistent standard error estimator, these violations were not a major concern (Hayes \& Cai 2007; Hayes 2018). We chose not to control for age, as age differences between the study groups reflect natural variations that could impact legal decision-making; however, to ensure that our results were not primarily attributed to this decision, we ran the analyses with and without age as a covariate. We found no changes in significance for any of the analyses when controlling for age. We chose to control for gender, because while the forensic group being entirely male is an accurate reflection of reality, the non-forensic groups being primarily female does not reflect the gender distribution found in the Canadian public. To better understand the relationship between legal decision-making and participant gender, we report any changes in significance associated with the use of this covariate.

\section{Results}

Attitudes toward the treatment of PCSO were significantly different between the study groups, $F(3,171)=30.92, p<.0001, \eta_{\mathrm{p}}{ }^{2}=.35$, with the most negative attitudes reported by the UG group $(M=2.75, S D=0.42)$, followed by the GP $(M=2.53, S D=0.54)$, and PCSO-C groups $(M=1.84, S D=0.26)$. Degree of Support for 161 orders was also significantly different, $F(3,171)=18.20, p<.0001, \eta_{\mathrm{p}}^{2}=.24$, with participants in both the GP $(M=3.92, S D=0.65)$ 
INTERPRETATION AND ENFORCEMENT OF CANADA'S 161 ORDER

and UG groups $(M=3.86, S D=0.67)$ showing greater support than forensic participants $(M=$ 2.94, $S D=0.78)$. All three groups reported the least support for Condition (d), prohibiting Internet use, and the most support for Condition (a.1), prohibiting proximity to the victim's residence. Mean Could Breach scores were not significantly different between groups, $F(3,375)$ $=0.503, p=.681, \eta_{\mathrm{p}}^{2}=.01$, whereas mean Should Breach scores were higher for the UG group $(M=0.28, S D=0.19)$ compared to both the GP $(M=0.17, S D=0.17)$ and PCSO-C groups $(M=$ $0.11, S D=0.12), F(3,375)=10.70, p<.0001, \eta_{\mathrm{p}}^{2}=.16$. We found no changes in significance when not controlling for gender. A number of significant correlations emerged between the demographic factors, predictors, and study measures; we do not discuss these here due to space limitations, but correlations can be found in Appendix C.

\section{Breach Decisions by Scenario}

Figure 1 shows the proportion of the total sample reporting that each scenario: (1) could and should constitute a breach; (2) could not and should not constitute a breach; and (3) could but should not constitute a breach. Regardless of group membership, the rate at which participants reported the scenarios could constitute a breach was higher than the rate at which they felt they should constitute a breach. Some scenarios - and by extension certain behaviours and conditions - showed greater discrepancy, particularly among Should Breach scores (for a breakdown of breach scores by group, see Appendix D). The only scenario that most participants agreed could and should constitute a breach involved attending a community centre, which is explicitly prohibited in Condition (a). There were four scenarios for which approximately half the forensic sample (40\% to $60 \%$ ) disagreed on whether the behaviour could constitute a breach (i.e., highway rest stop, registration kiosk, riding the bus, McDonald's drive-thru). This demonstrates that even people subject to a 161 order do not necessarily agree on what behaviours 
INTERPRETATION AND ENFORCEMENT OF CANADA'S 161 ORDER

are prohibited. It is worth noting that there was one scenario (\#10) for which forensic participants were more likely than non-forensic participants to report the scenario should result in a breach; this involved attending a beer garden that was located on the edge of a park/beach but could be accessed from the street.

[Figure 1 about here]

\section{Simple Mediation Models}

We report the unstandardized regression coefficients for all models, and the partially standardized effect sizes for any significant direct or indirect effects. As mentioned above, these terms refer specifically to unmediated (direct) versus mediated (indirect) effects, and should not be interpreted as implying causation.

\section{Direct Effects of Group Membership (H1)}

Table 2 presents the results for H1a and H1b. As expected, we found that when using Could Breach scores $\left(Y_{1}\right)$ as the outcome variable, the model summary test for the direct effect of Group on Breach scores when controlling for Attitude $(M)$ was not significant, $F(4,171)=1.12$, $p=.349$, nor were the relative direct effects for either the GP, $t(94)=-0.09, p=.929$, or UG groups, $t(118)=-0.13, p=.895$. When using Should Breach scores $\left(Y_{2}\right)$, the direct effect of Group on Breach scores when controlling for Attitude was significant, $F(4,170)=11.94, p<$ .0001; however, the relative direct effects were not significant for membership in either the GP, $t(94)=-1.13, p=.262$, or UG groups, $t(118)=1.29, p=.200(\mathrm{H} 1 b)$. Hayes $(2018)$ notes that it is still reasonable in this situation to conclude that $X$ does directly affect $Y$. Our findings were consistent with our hypothesis (H1) that group membership would have a direct effect on Should Breach but not Could Breach scores (i.e., subjective and objective enforcement decisions, respectively), independent of any (potential) relationship between group membership and 
INTERPRETATION AND ENFORCEMENT OF CANADA'S 161 ORDER

attitudes toward the treatment of PCSO. When not controlling for gender, the relative direct effect of Group on Should Breach scores became significant for the UG group $\left(p=.043, c^{\prime}\right.$ ps $=$ .43). This suggests the possibility that undergraduate students' subjective legal enforcement decisions may have been associated with gender.

[Table 2 about here]

\section{Indirect Effects of Group Membership through Attitude (H2a)}

The results for $\mathrm{H} 2$ are presented at the bottom of Table 2. Contrary to our expectation, the relative indirect effects of Group on Could Breach scores through Attitude were significant for both the GP, $\beta=-.05, \mathrm{CI}=[-.10,-.001], a b_{\mathrm{ps}}=[-.46,-.004]$, and $\mathrm{UG}$ groups, $\beta=-.06, \mathrm{CI}=[-.12$, $-.001], a b_{\mathrm{ps}}=[-.53,-.004]$. When not controlling for gender, however, these results were no longer significant for either the GP, CI $=[-.10, .001]$ or UG groups, $\mathrm{CI}=[-.12, .001]$. As predicted, we found that the relative indirect effects of Group on Should Breach scores through Attitude were significant for both the GP, $\beta=.08, \mathrm{CI}=[.03, .13], a b_{\mathrm{ps}}=[.16, .70]$, and UG groups, $\beta=.09, \mathrm{CI}=[.03, .14], a b_{\mathrm{ps}}=[.19, .77]$. There were no changes in significance when not controlling for gender. These findings are consistent with our theory that attitudes toward the treatment of PCSO may function as one potential mechanism through which membership in the non-forensic (relative to forensic) groups decreased the likelihood of reporting the scenarios could constitute a breach, and increased the likelihood of reporting they should constitute a breach. The indirect effect of group membership on objective (but not subjective) enforcement decisions appeared to be associated with gender.

Individual Pathways in Indirect Effect. The effect of Group on Attitude (i.e., path a) was significant in all models, with more negative Attitudes reported by both the GP, $t(94)=5.19$, $p<.0001$, and UG groups, $t(118)=6.66, p<.0001$, relative to the PCSO-C group. The effects of 
INTERPRETATION AND ENFORCEMENT OF CANADA'S 161 ORDER

Attitude on Breach scores independent of group membership (i.e., path $b$ ) did not reach significance when using Could Breach scores as the outcome variable, $t(174)=-1.78, p=.077$, but was significant for Should Breach scores, $t(174)=3.42, p=.001$. This is in line with our hypothesis that attitudes toward the treatment of PCSO would be significantly associated with subjective, but not objective, enforcement decisions, and consistent with the idea that more negative attitudes would be associated with a greater likelihood of reporting the scenarios should constitute a breach. We found no changes in significance when not controlling for gender.

Figure 2 shows the estimated regression coefficients for the relative unconditional direct and indirect effects of Group on Breach scores through Attitude.

[Figure 2 about here]

\section{Conditional Effects of Group Membership (H2b)}

As expected, when using Could Breach scores as the outcome variable, the relative conditional direct effects were not significant for either Group, $F(2,166)=1.65, p=.195$, or Attitude, $F(1,167)=0.08, p=.782$, and the relative conditional indirect effects of Group on Could Breach scores through Attitude were not significant for either the GP, CI $=[-.09, .07]$, or UG groups, $\mathrm{CI}=[-.11, .08]$. Contrary to our hypothesis, we also found non-significant results for the relative conditional direct effects of both Group, $F(2,166)=0.44, p=.646$, and Attitude, $F(1,166)=0.85, p=.358$, on Should Breach scores, as well as for the relative conditional indirect effects of membership in the GP, CI $=[-.02, .07]$, or UG groups, $\mathrm{CI}=[-.03, .08]$ (see Appendix E for estimated regression coefficients).

These findings were not consistent with our hypothesis that objective and subjective enforcement decisions would be significantly different for participants with "low", "moderate", or "high" levels of support for 161 order conditions. It is worth noting, however, that bivariate 
INTERPRETATION AND ENFORCEMENT OF CANADA'S 161 ORDER

correlations showed that membership in the GP and UG groups was significantly correlated with increased support for 161 orders $(r=.21$ for both). Increased support was significantly correlated with both negative attitudes toward PCSO $(r=.36)$ and a higher rate of reporting the scenarios should constitute a breach $(r=.26)$.

\section{Discussion}

We sought to explore possible inconsistencies in how the 161 order conditions were interpreted and enforced by forensic versus non-forensic groups, and whether these inconsistencies were associated with group membership, attitudes toward the treatment of PCSO, or support for 161 orders. Results were consistent with our theory that forensic and non-forensic participants hold different attitudes toward the treatment of PCSO, and that the subjective enforcement of 161 order conditions may be at least partially attributed to these attitudes. Participants who expressed more negative attitudes regarding the possibility of effectively treating PCSO were more likely to report that the scenarios should constitute a breach; this was true regardless of whether we controlled for gender. Our finding is in line with previous research in which more negative attitudes toward PCSO were associated with greater support for harsher and more punitive risk management strategies (Corăbian 2016; Jung et al. 2018). Contrary to our expectation, the indirect effect of group membership on objective enforcement decisions was also significant, although only when controlling for gender.

Neither objective nor subjective enforcement decisions were found to be conditional on participants' degree of support for 161 order conditions. However, membership in the nonforensic groups was positively correlated with support for 161 orders, and higher levels of support were correlated with more negative attitudes and a higher rate of reporting the scenarios should result in a breach. This raises the possibility that null findings regarding support for 161 
INTERPRETATION AND ENFORCEMENT OF CANADA'S 161 ORDER

orders could potentially relate to insufficient power, poor operationalization of the support construct, or our decision to examine support as a moderator rather than a predictor or mediator.

\section{Ambiguity and Overbreadth}

Prior to this study, anecdotal evidence from patient interactions and multiple constitutional challenges indicated that the ambiguous terminology used in s. 161, particularly the term "public park" in Condition (a), may have allowed too much individual discretion when interpreting and enforcing this condition. Our findings were consistent with this perspective, as the three scenarios involving a "public park" of some sort (i.e., highway rest stop, adults-only park, beer tent near park/beach) showed considerable variation with regard to whether participants believed the scenario could constitute a breach. The only scenario that most participants agreed could and should constitute a breach involved attending a community centre, which is explicitly prohibited in Condition (a). The definition of a community centre also allows less room for interpretation, although misinterpretations are still possible (see $R v$ Allaby, 2017 SKCA 25).

Interestingly, in $R v$ Budreo (W.), 2000 OAC 105, the Ontario Court of Appeal determined that by including a prohibition against "community centres", the 810.1 recognizance order was "overly broad contrary to s. 7 of the Charter" (at para. 9), and the prescribed solution was to remove this term. Concerns about ambiguity and overbreadth related to Condition (a)'s prohibition against places "where children under age 16 are reasonably expected to be" - which according to some judicial interpretations could be almost anywhere - are particularly important given that the intended purpose of this specifier was to limit the scope of this condition in order to avoid violating s. 7 (see $R v$ Heywood, 19943 SCR 761). 
INTERPRETATION AND ENFORCEMENT OF CANADA'S 161 ORDER

Participants were also divided on whether using a patient registration kiosk at a walk-in clinic could constitute a breach, which is one example of the potential (presumably unintended) consequences of prohibiting the use of "other digital networks". Considering the wide-range of technological advances that have been made since Condition (d) was introduced in 2012 (Safe Streets and Communities Act, SC 2012 c. 1), the implications of a potentially life-long prohibition against using the Internet or "digital networks" are likely different than when this condition was first implemented. The rising ubiquitousness of technology in everyday life may ultimately make adhering to Condition (d) - at least in its current form - nearly impossible. Since Internet prohibitions are typically monitored through the "honour system", a more effective strategy may be to prohibit the use of illegal or problematic websites (as in $R v$ Brar, 2016 ONCA 724), rather than banning Internet use entirely. Another strategy would be to permit Internet use during the probationary period so that safe and legal use of this tool can be promoted while PCSO-C (and their Internet use) are under supervision, ideally making subsequent Internet prohibitions unnecessary.

\section{Implications and Future Directions}

Given that police officers' limited time and resources are being allocated to the enforcement of 161 orders, important next steps include exploring objective and subjective enforcement decisions among law enforcement officers (and possibly other legal professionals) and attempting to identify other potential mediators and moderators that may help to explain observed differences in the interpretation and enforcement of 161 orders. A large scale investigation of Canadian police officers' attitudes toward community-based risk management strategies for PCSO - such as that conducted by Harris et al. (2015) in the United States - would also be beneficial. Longitudinal studies examining the relationship between imposed conditions 
INTERPRETATION AND ENFORCEMENT OF CANADA'S 161 ORDER

and recidivism rates are also greatly needed, and could potentially include comparisons of PCSO subject to s. 161, s. 810 , or regular probation conditions. Other strategies (currently underway) include exploring people's self-identified reasons for their objective and subjective enforcement decisions, examining PCSO-C's views regarding the personal impact of being subject to a 161 order, and conducting a thorough review of judicial decisions involving s. 161.

In order for research on this topic to potentially result in policy implications and recommendations, future studies will require larger and more representative samples, as well as the use of more reliable research designs (see Nunes, Pedneault, Filleter, Maimone, Blank, \& Atlas 2019). In particular, studies using experimental manipulations are needed to identify potentially causal factors associated with differences in the interpretation and enforcement of the 161 order conditions. One possible manipulation could involve providing participants with either the original s.161 or a version modified to reduce ambiguity, and assessing whether this has an impact on objective or subjective enforcement decisions. Based on past research suggesting that exposure to empirical evidence has the potential to cause at least short-term changes in Canadian's opinions on criminal justice policies (Bousfield, Cook, \& Roesch 2014), future studies could also explore the impact of providing participants with information regarding the rate of sexual recidivism and the efficacy of treatment interventions compared to risk management strategies. Ideally, this would help to inform strategies aimed at reducing negative and stigmatizing public attitudes toward PCSO, which may ultimately contribute to the prevention of both initial sexual offences and recidivism (Knack, Winder, Murphy, \& Fedoroff 2019). 
INTERPRETATION AND ENFORCEMENT OF CANADA'S 161 ORDER

\section{Limitations}

A number of important limitations should be considered when interpreting our results. Most importantly, the results cannot be used to support the existence of causal relationships, as no experimental manipulation was introduced. Although findings were consistent with our theory that attitudes toward PCSO function as one contributing factor underlying the relationship between group membership and subjective legal decision-making, these results do not account for the many unexplored factors that could also help to explain the observed effects. Similarly, while we expected that our samples would differ in their attitudes toward PCSO, the fact that they also differed on several other characteristics (e.g., age, gender, political views) makes it difficult to discern which combination of factors may be contributing to these effects (see Appendix F for demographic comparisons between groups). A lack of representativeness among our samples could also have resulted in more biased population estimates and insufficient power to detect group differences (despite our a priori power analysis), thereby increasing the Type II error rate (Jager, Putnick, \& Bornstein 2017).

Furthermore, our recruitment methods prohibited us from obtaining information on participation rate, and our use of small, non-representative samples prevents us from generalizing the observed effects to larger populations of Canadian undergraduate students, community members, or PCSO-C. However, the fact that we were able to include a sample of participants that are actually subject to 161 orders should be seen as a strength of this study. Finally, all outcome measures except the Attitude scale were created for this study and therefore lack independent information concerning their reliability or validity. Despite these limitations, we believe this study was an informative first step toward an empirical understanding of 161 orders, and supports the need for future research on this topic. 
INTERPRETATION AND ENFORCEMENT OF CANADA'S 161 ORDER

\section{Conclusions}

Community-based risk management strategies for people convicted of sexual offences, including 161 orders, appear to disregard the well-established finding that most PCSO-C meet their victims and commit their offences in private (often residential) settings. In fact, the stereotypical "predatory offender" - for whom these strategies may actually be appropriate makes up only $1 \%$ to $4 \%$ of this population (Colombino, Mercado, \& Jeglic 2009; Rotenberg 2017). According to desistance theory, "Distorted and relentlessly punitive attitudes constitute obstacles to successful behavioral change, and ultimately, may well result in increased rather than lesser risk of further offending" (Willis, Levenson, \& Ward 2010: 552). As such, the continued use of risk management strategies that are inherently punitive and based on public fears and misconceptions about sexual offending must be called into question. If society truly wants to protect children from sexual abuse, it is imperative that these strategies be based on empirical and methodologically sound research (Lussier, McCuish, \& Cale 2020; Myers 2014), as opposed to public fears and inaccurate assumptions about PCSO-C.

The Canadian governments' ongoing refusal to make the sex offender registries publicly available, along with the limited use of public notifications and lack of formal residency restrictions, suggests an appreciation for evidence-based approaches to preventing sexual offences. However, certain conditions included in s. 161 reflect outdated and incorrect beliefs about the nature of sexual offences against children (e.g., "stranger danger"). This may relate to the fact that some conditions have remained unchanged since 1993, and thus do not account for nearly 30 years of scientific discovery and advancement in this field. Past research demonstrating low rates of sexual recidivism and a lack of empirical support for other community-based risked management strategies, suggest that a re-evaluation of existing legislative policies may be 
INTERPRETATION AND ENFORCEMENT OF CANADA'S 161 ORDER

warranted. We argue that any such re-evaluation conducted in a Canadian context should include s. 161 orders. Since evidence-based policy recommendations will require considerably more research into the application, efficacy, and collateral consequences associated with s. 161, we hope this study will encourage further investigation into this Canadian risk management strategy.

Funding and Disclosure Statement. This research was unfunded and conducted as part of a Master's thesis. The authors report no financial interests or benefits resulting from this research. 
INTERPRETATION AND ENFORCEMENT OF CANADA'S 161 ORDER

\section{References}

Ackerman, Alissa R., Jill S. Levenson, and Andrew J. Harris

2012 How many sex offenders really live among us? Adjusted counts and population rates in

five US states. Journal of Crime and Justice 35: 464-474.

Allison, Meredith, Laura Sweeney, and Sandy Jung

2013 A comparison of Canadian and American offender stereotypes. North American Journal of Psychology 15: 589-608.

Appelbaum, Paul S.

2008 Sex offenders in the community: Are current approaches counterproductive? Psychiatric

Services 59: 352-354.

Bousfield, N. Kate, Alana N. Cook, and Ronald Roesch

2014 Evidence-based criminal justice policy for Canada: An exploratory study of public opinion and the perspective of mental health and legal professionals. Canadian Psychology 55: 204-215.

Budd, Kristen M. and Christina Mancini

2016 Crime control theater: Public (mis)perceptions of the effectiveness of sex offender residence restrictions. Psychology, Public Policy, and Law 22: 362-374.

Call, Corey

2018 The collateral consequences of sex offender management policies: Views from

professionals. International Journal of Offender Therapy and Comparative Criminology 62: 676696.

Challinor, Laura and Simon Duff

2019 Forensic staff attitudes toward men who have sexually offended: A general public comparison. Journal of Forensic Nursing 15: 110-119.

Colombino, Nicole, Cynthia Calkins Mercado, and Elizabeth L. Jeglic 2009 Situational aspects of sexual offending: Implications for residence restriction laws. Justice Research and Policy 11: 27-43.

Corăbian, Gabriela

2016 Working towards desistance: Canadian public's attitudes towards sex offenders, sex offender treatment, and policy. Unpublished dissertation: 1-263

Corăbian, Gabriela and Neil Hogan

2012 Collateral effects of the media on sex offender reintegration: Perceptions of sex offenders, professionals, and the lay public. Sexual Offender Treatment 7: 1-10.

Craun, Sarah W. Catherine A. Simmons, and Kristen Reeves

2011 Percentage of named offenders on the registry at the time of the assault: Reports from sexual assault survivors. Violence Against Women 17: 1374-82. 
INTERPRETATION AND ENFORCEMENT OF CANADA'S 161 ORDER

Cubellis, Michelle A., Scott M. Walfield, and Andrew J. Harris

2018 Collateral consequences and effectiveness of Sex Offender Registration and Notification: Law enforcement perspectives. International Journal of Offender Therapy and Comparative Criminology 62: 1080-1106.

Dowler, Kenneth

2004 Comparing American and Canadian local television crime stories: A content analysis.

Canadian Journal of Criminology and Criminal Justice 46: 573-596.

Dowler, Kenneth

2006 Sex, lies, and videotape: The presentation of sex crime in local television news. Journal of Criminal Justice 34: 383-392.

Faul, Franz, Edgar Erdfelder, Albert-Georg Lang, and Axel Buchner

$2007 \mathrm{G} *$ Power3: A flexible statistical power analysis program for the social, behavioral, and biomedical sciences. Behavior Research Methods 39: 175-191.

Fortune, Clare Ann, Tony Ward, and Gwenda M. Willis

2012 The rehabilitation of offenders: Reducing risk and promoting better lives. Psychiatry, Psychology, and Law 19: 646-661.

Fritz, Matthew S. and David P. MacKinnon 2007 Required sample size to detect the mediated effect. Psychological Science 18: 233-239.

Flynt, Latreace N.

2016 Law enforcement officers attitudes towards sex offenders and SORNA policies. ProQuest Dissertations 10172475: 1-123.

Griffiths, Curt T., Yvon Dandurand, and Danielle Murdoch

2007 The social reintegration of offenders and crime prevention. Public Safety Canada: National Crime Prevention Centre. Research Report 2007-02: 1-53.

Hanson, R. Karl, Andrew J.R. Harris, Leslie Helmus, and David Thornton

2014 High-risk sex offenders may not be high-risk forever. Journal of Interpersonal Violence 29: 2792-2813.

Hanson, R. Karl, Andrew J.R. Harris, Elizabeth Letourneau, Leslie Maaike Helmus, and David Thornton

2018 Reductions in risk based on time offense-free in the community: Once a sexual offender, not always a sexual offender. Psychology, Public Policy, and Law 24: 48-63.

Harris, Andrew J., Chris Lobanov-Rostovsky, and Jill S. Levenson

2015 Law enforcement perspectives on sex offender registration and notification: Preliminary survey results. University of Massachusetts Lowell. 
INTERPRETATION AND ENFORCEMENT OF CANADA'S 161 ORDER

Hartley, Thomas and Bruce Russett

1992 Public opinion and the common defense: Who governs military spending in the United States? American Political Science Review 86: 905-115.

Hayes, Andrew F.

2018 Introduction to Mediation, Moderation, and Conditional Process Analysis. New York: Guilford Press.

Hogue, Todd E.

1993 Attitudes towards prisoners and sexual offenders. Issues in Criminological \& Legal Psychology 19: 27-32.

Humphrey, Tamara and Erin Gibbs Van Brunschot 2018 Accumulating (dis)advantage: Do social bonds mediate the relationship between multiple childhood adversities and persistent offending? Journal of Developmental and Life-Course Criminology 4: 297-321.

Hutchinson, Allan C.

2010 In the park: A jurisprudential primer. Osgoode Hall Law Journal 48.2: 337-356.

Jager, Justin, Diane L. Putnick, and Marc H. Bornstein

2017 More than just convenient: The scientific merits of homogeneous convenience samples. Monographs of the Society for Research in Child Development 82: 13-30.

Johnson, Helen, J. Gary Hughes, and Jane L. Ireland 2007 Attitudes towards sex offenders and the role of empathy, locus of control and training: A comparison between a probationer police and general public sample. The Police Journal 80: 2854.

Jung, Sandy, Meredith Allison, and Erin Martin 2018 Perspectives of Americans and Canadians on the use and function of sex offender registries. International Journal of Law, Crime and Justice 52: 106-117.

Kjelsberg, Ellen and Liv Heian Loos

2008 Conciliation or condemnation? Prison employees' and young peoples' attitudes towards sexual offenders. International Journal of Forensic Mental Health, 7: 95-103.

Knack, Natasha, Belinda Winder, Lisa Murphy, and J. Paul Fedoroff

Primary and secondary prevention of child sexual abuse. International Review of Psychiatry 31: 181-194.

Levenson, Jill S.

2018 Sex offender management policies and evidence-based recommendations for registry reform. Current Psychiatry Reports 20: 1-7.

Levenson, Jill S., David A. D'Amora, and Andrea L. Hern 
INTERPRETATION AND ENFORCEMENT OF CANADA'S 161 ORDER

2007 Megan's Law and its impact on community re-entry for sex offenders. Behavioral Science and Law 25: 587-602.

Levenson, Jill S., Yolanda N. Brannon, Timothy Fortney, and Juanita Baker 2007 Public perceptions about sex offenders and community protection policies. Analyses of Social Issues and Public Policy 7: 137-161.

Lussier, Patrick, Nadine Deslauriers-Varin, and Tricia Râtel

2010 A descriptive profile of high-risk sex offenders under intensive supervision in the province of British Columbia, Canada. International Journal of Offender Therapy and Comparative Criminology 54: 71-91.

Lussier, Patrick and Carmen L.Z. Gress

2014 Community re-entry and the path toward desistance: A quasi-experimental longitudinal study of dynamic factors and community risk management of adult sex offenders. Journal of Criminal Justice 42: 111-122.

Lussier, Patrick and Evan McCuish

2016 Desistance from crime without reintegration: A longitudinal study of the social context and life course path to desistance in a sample of adults convicted of a sex crime. International Journal of Offender Therapy and Comparative Criminology 60: 1791-1812.

Lussier, Patrick, Evan C. McCuish, and Jesse Cale

2020 Understanding Sexual Offending: An Evidence-Based Response to Myths and

Misconceptions. Switzerland: Springer Nature.

Lynch, Mona

2002 Pedophiles and cyber-predators as contaminating forces: The language of disgust, pollution, and boundary invasions in federal debates on sex offender legislation. Law \& Social Inquiry $27: 529-566$.

MacAulay, Lawrence.

2001 High-risk offenders: A handbook for criminal justice professionals. Solicitor General Canada.

Mancini, Christina, J.C. Barnes, and Daniel P. Mears 2013 It varies from state to state: An examination of sex crime laws nationally. Criminal Justice Policy Review 24: 166-198.

Maryniuk, Jonathan.

2008 Interpreting Section 7 of the Charter: Clarity, vagueness and overbreadth. The Charter, legal rights (sections 7-14). Centre for Constitutional Studies.

McAlinden, Anne-Marie 2007 The Shaming of Sex Offenders: Risk, Retribution and Reintegration. Portland: Hart Publishing. 
INTERPRETATION AND ENFORCEMENT OF CANADA'S 161 ORDER

Murphy, Lisa and Paul Fedoroff

2013 Sexual offenders' views of Canadian sex offender registries: A survey of a clinical sample. Canadian Journal of Behavioural Science 45: 238-249.

Murphy, Lisa, J. Paul Fedoroff, and Melissa Martineau

2009 Canada's sex offender registries: Background, implementation, and social policy considerations. The Canadian Journal of Human Sexuality 18: 61-72.

Mustaine, Elizabeth Ehrhardt, Richard Tewksbury, David P. Connor, and Brian K. Payne 2015 Criminal justice officials' views of sex offenders, sex offender registration, community notification, and residency restrictions. Justice System Journal 36: 63-85.

Myers, David L.

2013 Offender reentry and reintegration: Policy and research. Criminal Justice Policy Review 24: 3-8.

Nelson, Meredith, Barbara Herlihy, and Jeffrey Oescher 2002 A survey of counselor attitudes towards sex offenders. Journal of Mental Health Counseling 24: 51-67.

Nunes, Kevin L., Chloe I. Pedneault, W. Eric Filleter, Sacha Maimone, Carolyn Blank, and Maya Atlas 2019 “I know correlation doesn't prove causation, but...": Are we jumping to unfounded conclusions about the causes of sexual offending? Sexual Abuse 31: 220-236.

Olver, Mark E. and Ashley A. Barlow 2010 Public attitudes toward sex offenders and their relationship to personality traits and demographic characteristics. Behavioral Sciences \& the Law 28: 832-849.

Petrunik, Michael G.

2002 Managing unacceptable risk: Sex offenders, community response, and social policy in the United States and Canada. International Journal of Offender Therapy and Comparative Criminology 46: 483-511.

Petrunik, Michael G.

2003 The hare and the tortoise: Dangerousness and sex offender policy in the United States and Canada. Canadian Journal of Criminology and Criminal Justice 45: 43-72.

Petrunik, Michael, Lisa Murphy, and J. Paul Fedoroff 2008 American and Canadian approaches to sex offenders: A study of the politics of dangerousness. Federal Sentencing Reporter 21: 111-123.

Powell, Martine, Andrew Day, Mairi Benson, James Vess, and Joe Graffam 2014 Police officers' perceptions of interviewing offenders on Sex Offender Registries. International Journal of Police Science \& Management 16: 255-266. 
INTERPRETATION AND ENFORCEMENT OF CANADA'S 161 ORDER

\section{Rotenberg, Cristine}

2017 Police-reported sexual assaults in Canada, 2009 to 2014: A statistical profile. Canadian

Centre for Justice Statistics: ISSN 1209-6393

Sandler, Jeffrey C., Naomi J. Freeman, and Kelly M. Socia

2008 Does a watched pit boil? A time-series analysis of New York State's Sex Offender

Registration and Notification Law. Psychology, Public Policy, and Law 14: 284-302.

Sharpe, Elaine

1999 The Sometime Connection: Public Opinion and Social Policy. Albany, NY: SUNY Press.

Soroka, Stuart N. and Christopher Wlezien

2004 Opinion representation and policy feedback: Canada in comparative perspective. Canadian Journal of Political Science 37: 531-559.

Soroka, Stuart N. and Christopher Wlezien

2010 Degrees of Democracy: Politics, Public Opinion, and Policy. Cambridge University Press.

Spoo, Susanne, Leah E. Kaylor, Sarah Schaaf, Michelle Rosselli, Anniken Laake, Christina

Johnson, and Elizabeth L. Jeglic

2018 Victims' attitudes toward sex offenders and sex offender legislation.

International Journal of Offender Therapy and Comparative Criminology 62: 3385-3407.

Statistics Canada

2017 Focus on geography series, 2016 Census. Statistics Canada Catalogue no. 98-404-

X2016001. Ottawa, Ontario. Data products, 2016 Census.

Statistics Canada.

2020 Analysis: Population by age and sex. Annual Demographic Estimates: Canada, Provinces and Territories, 2020.

Tamang, Ritendra

2009 Portrayal of crime in televised news in Canada: Distortion and privileges. The Journal of the Institute of Justice \& International Studies 9: 193-199.

Uggen, Christopher, Jeff Manza, and Melissa Thompson 2006 Citizenship, democracy, and the civic reintegration of criminal offenders. Annals of American Academy of Political and Social Science 605: 281-310.

Vásquez, Bob Edward, Sean Maddan, and Jeffrey T. Walker 2008 The influence of sex offender registration and notification laws in the United States: A time-series analysis. Crime \& Delinquency 54: 175-192.

Willis, Gwenda M. and Randolph C. Grace 
INTERPRETATION AND ENFORCEMENT OF CANADA'S 161 ORDER

2009 Assessment of community reintegration planning for sex offenders: Poor planning predicts recidivism. Criminal Justice and Behavior 36: 494-512.

Wlezien, Christopher

2004 Patterns of representation: Dynamics of public preferences and policy. The Journal of Politics 66: 1-24.

Willis, Gwenda M., Jill S. Levenson, and Tony Ward 2010 Desistance and attitudes towards sex offenders: Facilitation or hindrance? Journal of Family Violence 25: 545-556.

Wnuk, Dorota, Jason E. Chapman, and Elizabeth L. Jeglic 2006 Development and refinement of a measure of attitudes toward sex offender treatment. Journal of Offender Rehabilitation 43: 35-47.

Zandbergen, Paul A., Jill S. Levenson, and Timothy C. Hart

2010 Residential proximity to schools and daycares: An empirical analysis of sex offense recidivism. Criminal Justice and Behavior 37: 482-502.

Zgoba, Kristen M. and Karen Bachar

2009 Sex offender registration and notification: Limited effects in New Jersey. U.S. Department of Justice.

\section{Legislation}

Canadian Charter of Rights and Freedoms, s 7, Part 1 of the Constitution Act, 1982, being Schedule B to the Canada Act 1982 (UK), 1982, c 11.

Criminal Code, RSC 1985, c C-46.

Criminal Code, RSC 1985, c C-46, s 161(1).

Criminal Code, RSC 1985, c C-46, s 179(1)(b).

Criminal Code, RSC 1985, c C-46, s 753.

Criminal Code, RSC 1985, c C-46, s 753.1.

Criminal Code, RSC 1985, c C-46, s 810.

Safe Streets and Communities Act, SC 2012 c. 1.

Sex Offender Information Registration Act, SC 2004, c. 10.

\section{Jurisprudence}


INTERPRETATION AND ENFORCEMENT OF CANADA'S 161 ORDER

$R v$ Allaby, 2017 SKCA 25.

$R v$ Brar, 2016 ONCA 724.

$R v$ Budreo (W.), 2000 OAC 105.

$R v$ Heywood, 1992 BCCA 6008.

$R v$ Heywood, 19943 SCR 761.R v Lachapelle, 2008 BCJ 728.

$R v$ Levkovic, 2013 SCC 25.

$R v$ McIntosh, 19951 SCR 686.

$R v$ Perron, 2009 ONCA 498. 
INTERPRETATION AND ENFORCEMENT OF CANADA'S 161 ORDER

Table 1

Description of Study Groups

\begin{tabular}{lcccccc}
\hline & \multicolumn{2}{c}{ PCSO-C } & \multicolumn{2}{c}{ GP } & \multicolumn{2}{c}{ UG } \\
\cline { 2 - 7 } & $M$ & $S D$ & $M$ & $S D$ & $M$ & $S D$ \\
\hline Age & 52.3 & 12.0 & 33.7 & 11.2 & 21.2 & 6.1 \\
Exposure to info re: PCSO & 71.3 & 23.2 & 51.2 & 27.4 & 48.6 & 22.5 \\
Contact with PCSO & & & & & & \\
$\quad$ Personal & - & - & 10.0 & 2.5 & 7.7 & 2.5 \\
$\quad$ Professional & - & - & 13.2 & 3.6 & 4.6 & 1.9
\end{tabular}

Knowledge about PCSO

\begin{tabular}{|c|c|c|c|c|c|c|}
\hline \multirow{2}{*}{$\begin{array}{c}\text { Treatment } \\
\text { In general }\end{array}$} & \multirow[t]{2}{*}{-} & \multirow{2}{*}{-} & \multirow{2}{*}{$\begin{array}{l}32.6 \\
43.8\end{array}$} & \multirow{2}{*}{$\begin{array}{l}3.7 \\
3.4\end{array}$} & \multirow{2}{*}{$\begin{array}{l}29.7 \\
43.7\end{array}$} & \multirow{2}{*}{$\begin{array}{l}2.8 \\
2.9\end{array}$} \\
\hline & & & & & & \\
\hline & \multicolumn{2}{|c|}{ PCSO-C } & \multicolumn{2}{|c|}{ GP } & \multicolumn{2}{|c|}{$\mathrm{UG}$} \\
\hline & $n$ & $\%$ & $n$ & $\%$ & $n$ & $\%$ \\
\hline \multicolumn{7}{|l|}{ Gender } \\
\hline Males & 39 & 100 & 16 & 28.6 & 15 & 18.8 \\
\hline Females & 0 & 0.0 & 38 & 67.9 & 65 & 81.3 \\
\hline Non-binary & 0 & 0.0 & 2 & 3.6 & 0 & 0.0 \\
\hline \multicolumn{7}{|l|}{ Ethnicity $^{\mathrm{a}}$} \\
\hline Caucasian & 39 & 100 & 45 & 80.4 & 47.0 & 59.5 \\
\hline African Canadian & 0 & 0.0 & 1 & 1.8 & 3.0 & 3.8 \\
\hline Latin & 0 & 0.0 & 2 & 3.6 & 3.0 & 3.8 \\
\hline Asian & 0 & 0.0 & 5 & 8.9 & 12 & 15.2 \\
\hline Aboriginal & 0 & 0.0 & 1 & 1.8 & 3 & 3.8 \\
\hline Arab & 0 & 0.0 & 0 & 0.0 & 5 & 6.3 \\
\hline Mixed Race & 0 & 0.0 & 2 & 3.6 & 6 & 7.6 \\
\hline \multicolumn{7}{|l|}{ Education $^{\mathrm{a}}$} \\
\hline No diploma & 7 & 17.9 & 1 & 1.8 & 1 & 1.3 \\
\hline High school & 13 & 33.3 & 13 & 23.6 & 62 & 77.5 \\
\hline College & 11 & 28.2 & 6 & 10.9 & 14 & 17.5 \\
\hline Bachelor's & 6 & 15.4 & 21 & 38.2 & 2 & 2.5 \\
\hline Graduate & 2 & 5.1 & 14 & 25.4 & 1 & 1.3 \\
\hline
\end{tabular}


INTERPRETATION AND ENFORCEMENT OF CANADA'S 161 ORDER

\begin{tabular}{|c|c|c|c|c|c|c|}
\hline & \multicolumn{2}{|c|}{ PCSO-C } & \multicolumn{2}{|c|}{ GP } & \multicolumn{2}{|c|}{$\mathrm{UG}$} \\
\hline & $n$ & $\%$ & $n$ & $\%$ & $n$ & $\%$ \\
\hline \multicolumn{7}{|l|}{ Marital status } \\
\hline Single & 12 & 30.8 & 15 & 26.8 & 47 & 58.8 \\
\hline Dating & 3 & 7.7 & 12 & 21.4 & 28 & 35.0 \\
\hline Married/common-law & 11 & 28.2 & 28 & 50.0 & 4 & 5.1 \\
\hline Separated/divorced & 13 & 33.3 & 1 & 1.8 & 1 & 1.3 \\
\hline \multicolumn{7}{|l|}{ Employment $^{\mathrm{b}}$} \\
\hline Full time & 14 & 35.9 & 31 & 57.4 & 3 & 3.8 \\
\hline Part time & 8 & 20.5 & 9 & 16.7 & 34 & 42.5 \\
\hline Student & 0 & 0.0 & 4 & 7.4 & 37 & 46.3 \\
\hline Retired & 8 & 20.5 & 2 & 3.7 & 0 & 0.0 \\
\hline Unemployed & 9 & 23.1 & 8 & 14.9 & 6 & 7.6 \\
\hline \multicolumn{7}{|l|}{ Political views } \\
\hline Very Conservative & 1 & 2.6 & 0 & 0.0 & 0 & 0.0 \\
\hline Slight/moderate Con & 9 & 23.1 & 10 & 18.2 & 8 & 11.3 \\
\hline Neither Con/Lib & 10 & 25.6 & 5 & 9.1 & 24 & 33.8 \\
\hline Slight/moderate Lib & 9 & 23.1 & 22 & 40.0 & 24 & 33.8 \\
\hline Very Liberal & 3 & 7.7 & 14 & 25.5 & 11 & 15.5 \\
\hline Other & 7 & 17.9 & 4 & 7.3 & 4 & 5.6 \\
\hline Has children $^{\mathrm{a}}$ & 25 & 64.1 & 18 & 32.1 & 6 & 7.6 \\
\hline Hx of sexual abuse ${ }^{c}$ & 16 & 41.0 & 15 & 29.4 & 17 & 22.4 \\
\hline Forensic experience $^{\mathrm{d}}$ & 4 & 10.3 & 21 & 37.5 & 28 & 35.4 \\
\hline \multicolumn{7}{|c|}{ Primary source of information about sexual offending } \\
\hline Experience ${ }^{\mathrm{e}}$ & 34 & 87.2 & 0 & 0.0 & 0 & 0.0 \\
\hline News & 4 & 10.3 & 26 & 46.4 & 25 & 31.3 \\
\hline Social media & 0 & 0.0 & 8 & 14.3 & 34 & 42.5 \\
\hline Education/training & 1 & 2.6 & 15 & 26.8 & 14 & 17.5 \\
\hline Other & 0 & 0.0 & 7 & 12.5 & 7 & 8.8 \\
\hline
\end{tabular}

Note. PCSO-C = people convicted of sexual offences against children. $\mathrm{GP}=$ general public. $\mathrm{UG}=$ undergraduate students.

${ }^{\mathrm{a}} N=174 .{ }^{\mathrm{b}} N=173 .{ }^{\mathrm{c}} N=166 .{ }^{\mathrm{d}}$ Refers to studying, working, or volunteering in forensics.

${ }^{\text {e }}$ Refers to having been charged/convicted of a sexual offence. 


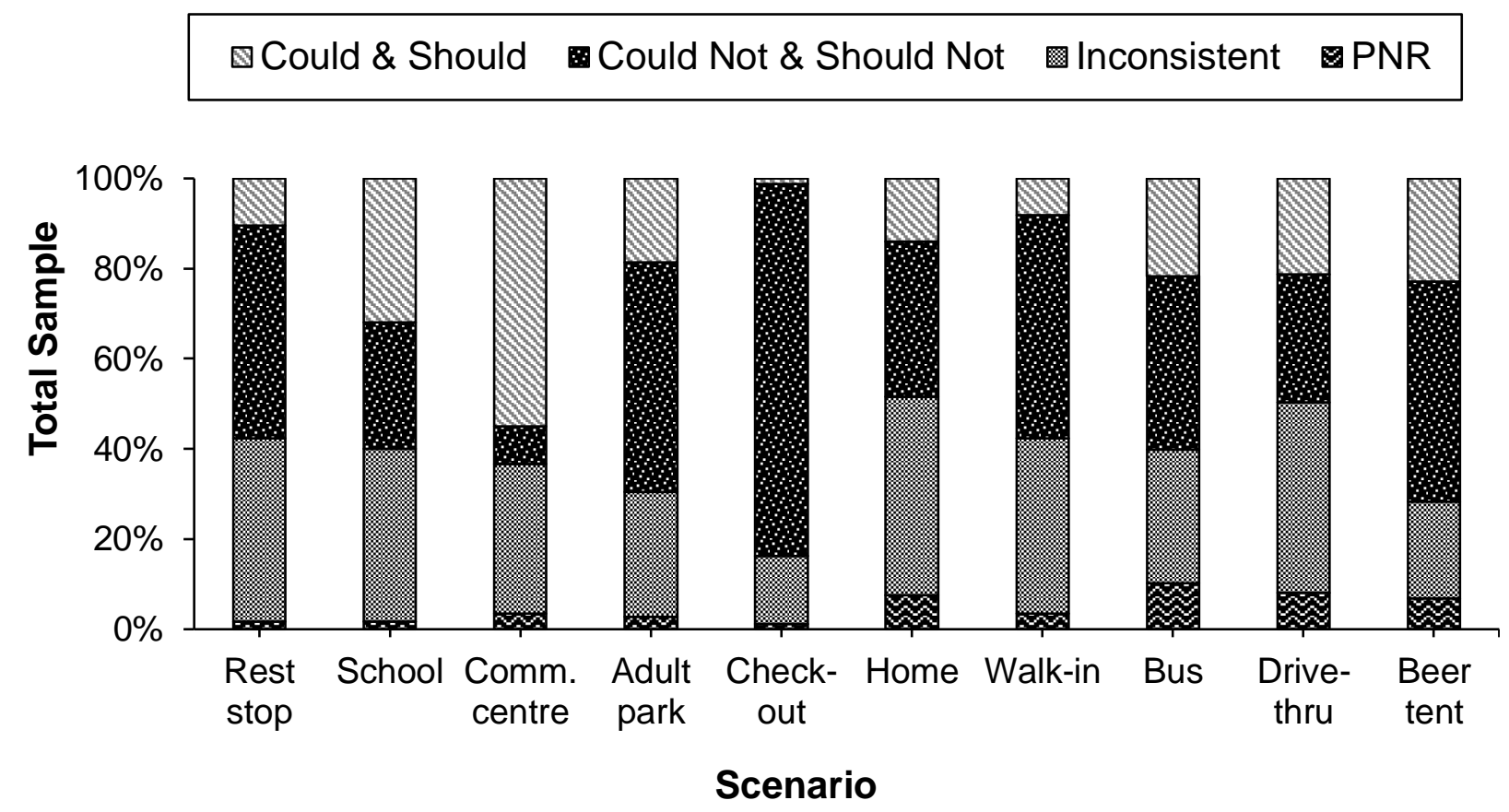

Note. Could \& Should = scenario could and should lead to a breach. Could Not \& Should Not = scenario could not and should not lead to a breach. Inconsistent $=$ scenario could but should not lead to breach. PNR = prefer not to respond. See Appendix B for full scenarios. 


\section{INTERPRETATION AND ENFORCEMENT OF CANADA'S 161 ORDER}

\section{Table 2}

Relative Direct and Indirect Effects of Group on Breach Scores through Attitude

\begin{tabular}{|c|c|c|c|c|c|c|c|c|c|c|c|}
\hline \multirow[b]{2}{*}{ Predictor } & \multirow[b]{2}{*}{ Path } & \multicolumn{5}{|c|}{ Could Breach $\left(Y_{1}\right)$} & \multicolumn{5}{|c|}{ Should Breach $\left(Y_{2}\right)$} \\
\hline & & $\beta$ & $S E$ & $t$ & $p$ & $95 \% \mathrm{CI}$ & $\beta$ & $S E$ & $t$ & $p$ & $95 \% \mathrm{CI}$ \\
\hline \multicolumn{12}{|c|}{ Relative direct effects } \\
\hline Constant & - & .74 & .08 & 9.29 & $<.0001$ & {$[.58, .90]$} & -.10 & .07 & -1.49 & .139 & {$[-.23, .03]$} \\
\hline$D_{1}(\mathrm{GP})$ & $c^{\prime} 1$ & -.01 & .07 & -0.09 & .929 & {$[-.13 .12]$} & -.05 & .04 & -1.13 & .262 & {$[-.12, .04]$} \\
\hline$D_{2}(\mathrm{UG})$ & $c^{\prime} 2$ & -.01 & .06 & -0.13 & .895 & {$[-.13, .12]$} & .06 & .04 & 1.29 & $.200^{\mathrm{d}}$ & {$[.03, .14]$} \\
\hline$M$ (Attitude) & $b$ & -.07 & .04 & -1.78 & .077 & {$[-.15, .01]$} & .11 & .03 & 3.42 & .001 & {$[.05, .18]$} \\
\hline Gender $^{\mathrm{a}}$ & - & .03 & .05 & 0.55 & .583 & {$[-.08, .13]$} & .03 & .03 & 1.01 & .312 & {$[-.03, .08]$} \\
\hline \multirow{2}{*}{\multicolumn{2}{|c|}{ Model summary }} & \multicolumn{5}{|c|}{$R^{2}=.029$} & \multicolumn{5}{|c|}{$R^{2}=.230$} \\
\hline & & \multicolumn{5}{|c|}{$F(4,171)=1.12, p=.349$} & \multicolumn{5}{|c|}{$F(4,171)=11.94, p<.0001$} \\
\hline \multicolumn{12}{|c|}{ Relative total effects } \\
\hline Constant & - & .61 & .04 & 16.35 & $<.0001$ & {$[.54, .68]$} & .11 & .02 & 5.70 & $<.0001$ & {$[.07, .15]$} \\
\hline$D_{1}(\mathrm{GP})$ & $c_{1}$ & -.05 & .06 & -0.92 & .361 & {$[-.17, .06]$} & .03 & .04 & 1.80 & .073 & {$[-.01, .11]$} \\
\hline$D_{2}(\mathrm{UG})$ & $c_{2}$ & -.07 & .06 & -1.16 & .247 & {$[-.17, .05]$} & .15 & .04 & 5.91 & $<.0001$ & {$[.11, .23]$} \\
\hline Gender $^{\mathrm{a}}$ & - & .03 & .05 & 0.62 & .535 & {$[-.06, .12]$} & .03 & .04 & 0.82 & .416 & {$[-.04, .10]$} \\
\hline \multirow{2}{*}{\multicolumn{2}{|c|}{ Model summary }} & \multicolumn{5}{|c|}{$R^{2}=.009$} & \multicolumn{5}{|c|}{$R^{2}=.158$} \\
\hline & & \multicolumn{5}{|c|}{$F(3,171)=0.46, p=.713$} & \multicolumn{5}{|c|}{$F(3,171)=12.36, p<.0001$} \\
\hline Predictor & Path & $\beta$ & Boo & $\operatorname{rap} S E$ & Boots & p 95\% CI & $\beta$ & Boot & $\operatorname{rap} S E$ & Boots & p 95\% CI \\
\hline \multicolumn{12}{|c|}{ Relative indirect effects } \\
\hline$D_{1}(\mathrm{GP})$ & $a_{1} b$ & -.05 & \multicolumn{2}{|c|}{.03} & \multicolumn{2}{|c|}{$[-.10,-.001]^{\mathrm{b}}$} & .08 & \multicolumn{2}{|c|}{.03} & \multicolumn{2}{|c|}{$[.03, .13]$} \\
\hline$D_{2}(\mathrm{UG})$ & $a_{2} b$ & -.06 & \multicolumn{2}{|c|}{.03} & \multicolumn{2}{|c|}{$[-.12,-.001]^{c}$} & .09 & \multicolumn{2}{|c|}{.03} & \multicolumn{2}{|c|}{$[.03, .15]$} \\
\hline
\end{tabular}

Note. Regression coefficients are unstandardized. Bootstrap $N=20,000 . \mathrm{GP}=$ general public. $\mathrm{UG}=$ undergraduates. $M=$ mediator .

${ }^{\mathrm{a}}$ Entered as covariate. ${ }^{\mathrm{b}}$ Without covariate, $\mathrm{CI}=[-.10, .001] .{ }^{\mathrm{c}}$ Without covariate, $\mathrm{CI}=[-.12, .001] .{ }^{\mathrm{d}}$ Without covariate, $p=.043$. 
eM

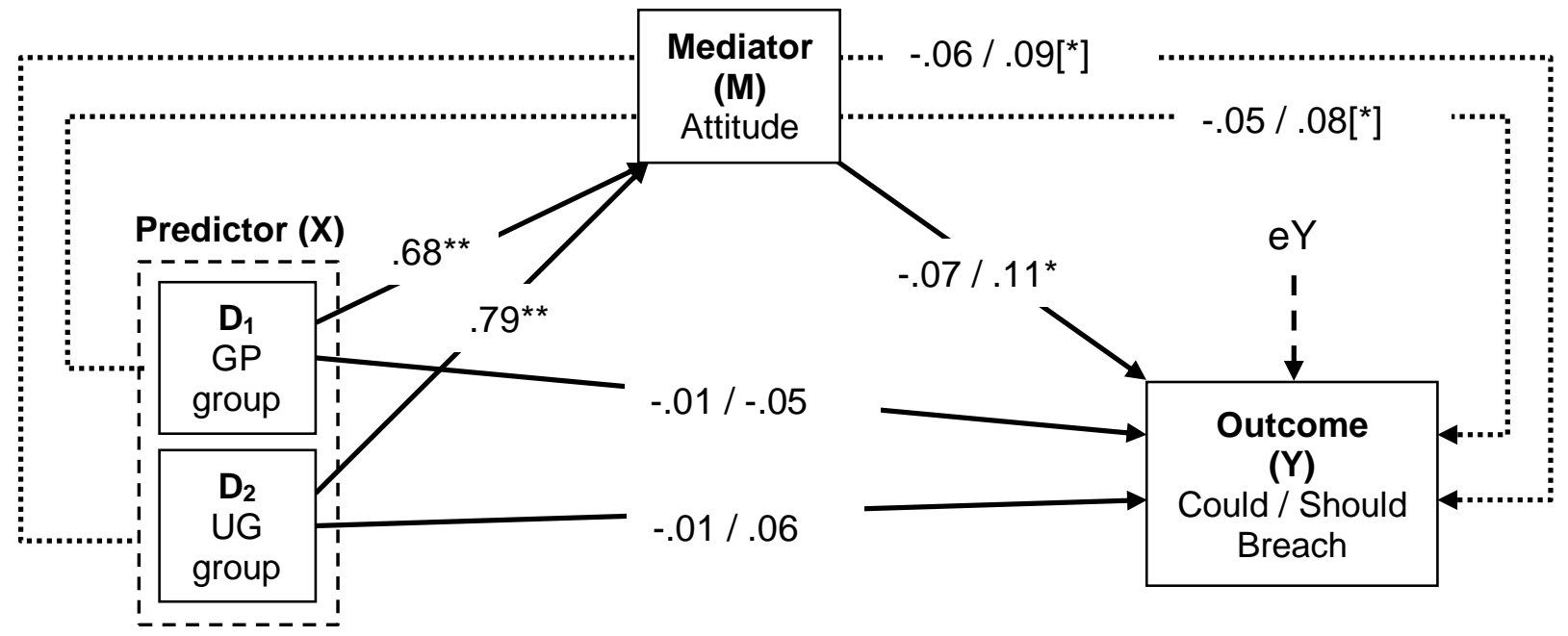

Note. Regression coefficients are unstandardized and controlling for gender. Dotted pathways represent indirect effects. Coefficients are for Could Breach model / Should Breach model. GP = general public. $\mathrm{UG}=$ undergraduate students. $\mathrm{eM}$ and $\mathrm{eY}$ represent error terms for the mediator and outcome variables, respectively. ${ }^{*} p<.01 .{ }^{* *} p<.001$. [*]Bootstrap 95\% CIs do not contain zero. 


\section{Appendix A}

\section{Order of prohibition}

161 (1) When an offender is convicted, or is discharged on the conditions prescribed in a probation order under section 730 , of an offence referred to in subsection (1.1) in respect of a person who is under the age of 16 years, the court that sentences the offender or directs that the accused be discharged, as the case may be, in addition to any other punishment that may be imposed for that offence or any other condition prescribed in the order of discharge, shall consider making and may make, subject to the conditions or exemptions that the court directs, an order prohibiting the offender from

(a) attending a public park or public swimming area where persons under the age of 16 years are present or can reasonably be expected to be present, or a daycare centre, schoolground, playground or community centre;

(a.1) being within two kilometres, or any other distance specified in the order, of any dwelling-house where the victim identified in the order ordinarily resides or of any other place specified in the order;

(b) seeking, obtaining or continuing any employment, whether or not the employment is remunerated, or becoming or being a volunteer in a capacity, that involves being in a position of trust or authority towards persons under the age of 16 years;

(c) having any contact — including communicating by any means — with a person who is under the age of 16 years, unless the offender does so under the supervision of a person whom the court considers appropriate; or

(d) using the Internet or other digital network, unless the offender does so in accordance with conditions set by the court. 


\section{Offences}

(1.1) The offences for the purpose of subsection (1) are

(a) an offence under section 151, 152 or 155, subsection 160(2) or (3), section 163.1, 170, $171,171.1,172.1$ or 172.2 , subsection $173(2)$, section $271,272,273$ or 279.011 , subsection $279.02(2)$ or $279.03(2)$, section 280 or 281 or subsection $286.1(2), 286.2(2)$ or $286.3(2)$;

(b) an offence under section 144 (rape), 145 (attempt to commit rape), 149 (indecent assault on female), 156 (indecent assault on male) or 245 (common assault) or subsection 246(1) (assault with intent) of the Criminal Code, chapter C-34 of the Revised Statutes of Canada, 1970, as it read immediately before January 4, 1983;

(c) an offence under subsection 146(1) (sexual intercourse with a female under 14) or section 153 (sexual intercourse with step-daughter), 155 (buggery or bestiality), 157 (gross indecency), 166 (parent or guardian procuring defilement) or 167 (householder permitting defilement) of the Criminal Code, chapter C-34 of the Revised Statutes of Canada, 1970, as it read immediately before January 1,1988; or

(d) an offence under subsection 212(1) (procuring), 212(2) (living on the avails of prostitution of person under 18 years), 212(2.1) (aggravated offence in relation to living on the avails of prostitution of person under 18 years) or 212(4) (prostitution of person under 18 years) of this Act, as it read from time to time before the day on which this paragraph comes into force.

\section{Duration of prohibition}

(2) The prohibition may be for life or for any shorter duration that the court considers desirable and, in the case of a prohibition that is not for life, the prohibition begins on the later of 
(a) the date on which the order is made; and

(b) where the offender is sentenced to a term of imprisonment, the date on which the offender is released from imprisonment for the offence, including release on parole, mandatory supervision or statutory release.

\title{
Court may vary order
}

(3) A court that makes an order of prohibition or, where the court is for any reason unable to act, another court of equivalent jurisdiction in the same province, may, on application of the offender or the prosecutor, require the offender to appear before it at any time and, after hearing the parties, that court may vary the conditions prescribed in the order if, in the opinion of the court, the variation is desirable because of changed circumstances after the conditions were prescribed.

\section{Offence}

(4) Every person who is bound by an order of prohibition and who does not comply with the order is guilty of

(a) an indictable offence and is liable to imprisonment for a term of not more than four years; or

(b) an offence punishable on summary conviction.

\author{
R.S., 1985, c. C-46, s. 161 R.S., 1985, c. 19 (3rd Supp.), s. 4 1993, c. 45, s. 1 1995, c. 22, s. 18 1997, c. 18 , s. 4 \\ 1999, c. 31, s. 67 2002, c. 13, s. 4 2005, c. 32, s. 5 2008, c. 6, s. 54 2012, c. 1, s. 16 2014, c. 21, s. 1, c. 25, s. 5 2015, \\ c. 23 , s. 62019 , c. 25 , s. 55
}




\section{Appendix B}

\section{Order Scenarios}

\section{Scenario \#1}

John is riding his motorcycle on a rural $(80 \mathrm{~km} / \mathrm{hr})$ highway, about an hour outside of Ottawa. After travelling for a while, he decides to take a break and pulls off the highway into a rest stop area. There are no restaurants, stores, or gas stations at the rest stop, just an area for cars to park and a washroom. Behind the parking lot is a large grassy area with a picnic table and a few trees scattered throughout, which leads down to a section of the Ottawa river. There is no one at the rest stop when John arrives. He parks his motorcycle and decides to walk along the water to stretch his legs.

\section{Scenario \#2}

John has recently gotten a job for a delivery catering company. His shift is from 3pm to $11 \mathrm{pm}$, and he works with two other employees. It is his responsibility to figure out the delivery routes and drive the truck. The other two employees are responsible for bringing the prepared food items into the venue. A few weeks later, John is asked to make a delivery to a local elementary school for a PTA meeting. Since the delivery would be made after school hours and he wouldn't be getting out of his truck, he decides it's okay to make the delivery.

\section{Scenario \#3}

John is looking for a new job now that he's been released into the community. He used to work in Information Technology (IT), but due to his conditions against using the Internet he needs to find a different line of work. He's been having trouble finding job opportunities because many are only posted online or require resumes to be submitted online. He learns about a job fair happening at a local community centre and thinks this could be a good opportunity to hand out 
some resumes. Since the job fair is for adults, and it's happening during the week when children would be in school, he decides to enter the community centre to attend the job fair.

\section{Scenario \#4}

John and his best friend had been camping together since they were kids, going multiple times every summer for many years now. It was one of the things that John looked forward to most. But since his conviction, it had become difficult to find a place to go, since many campgrounds are considered parks. One day a friend tells John about a section of Algonquin Park that is restricted to adults-only, meaning that no children are permitted in this area. Since children could not reasonably be expected to be present in an adults-only campground, John decides to go camping in this section of Algonquin Park [a provincial park in Ontario].

\section{Scenario \#5}

John is in the grocery store picking up something for dinner. After finding the few things he needs, he heads to the front of the store to pay and sees that all the cashiers have a long line of customers, many with full shopping carts. The only line that isn't currently busy is the selfcheckout line. John hesitates and wonders whether using a self-checkout machine could be interpreted as using the Internet or another digital network. Then he starts to wonder if maybe he's just being paranoid. After a few minutes, he uses the self-checkout to pay for his items and leaves the store.

\section{Scenario \#6}

John is at home making dinner. He has been sharing an apartment with his brother since he was charged with a sexual offence. The offence was against his step-daughter, who he is no longer able to see. John is worried because his brother has been away on a sailing trip and has been gone longer than planned. He's tried to contact his family members to see if they have any 
information, but they aren't speaking to him since his offence. There is a knock at the door and John pulls it open to find his step-daughter and her mother, coming to give him information about his brother.

\section{Scenario \#7}

John has recently come down with a cold, and after about a week of being sick he decides he should see a doctor to find out if he has some sort of infection. Since John doesn't have a family doctor, he goes to a local Appletree walk-in clinic. Inside the clinic John sees a sign telling patients to register themselves at the computer kiosk. Since John is worried that the computer might be connected to the Internet, he asks an employee at the front desk if he can register with her instead, but she tells him that all patients need to register at the kiosk. He walks back to the kiosk and registers himself on the computer.

\section{Scenario \#8}

John is riding the bus to work one day because his car is in the shop. He dislikes taking the bus since he has no way of knowing if someone under age 16 will get on. He avoids the back of the bus where younger people tend to sit, and always sits or stands near the front of the bus so he's easily visible to the bus driver. Today he's sitting in the second row of the bus when a girl around 13 or 14 gets on and takes the seat beside him. John immediately thinks about getting off at the next stop, but knows he'll be late for work if he has to wait for another bus, so he quickly stands up and moves away from the girl to another seat on the bus.

\section{Scenario \#9}

John is out running errands on the weekend and decides to go to McDonald's to get something for lunch. Since it's cold and raining outside, he decides to go through the drive-thru to get his food. When the employee comes on the intercom, he places his order and then pulls 
forward to the first window as instructed. He greets the employee at the window, hands over his money, and then pulls forward to collect his food. When the second window opens, he begins to greet the employee and then realizes that he is talking to his former victim. He stops talking immediately, takes the bag of food that is handed to him, and drives away.

\section{Scenario \#10}

John has been a member of an adult recreational volleyball league for many years, and his team always enters the Hope Volleyball tournament. This year, John has told his team that he cannot play in the tournament because it takes place at Mooney's Bay Park and Beach [a public area in Ottawa, ON]. John's teammates tell him that they're planning to go to the beer gardens once they finish playing for the day and suggest that he meets them there so they can all watch the concerts together. John decides that since the beer garden is for adults only and is located at the edge of the property (meaning he could enter it from the street without having to cross through the park), he will go meet his friends at the beer garden to watch the concerts. 


\section{Appendix C}

Correlations between Demographics, Predictors, and Study Measures for Total Sample

\begin{tabular}{|c|c|c|c|c|c|c|c|c|c|c|c|c|c|c|c|c|}
\hline Variable & 1 & 2 & 3 & 4 & 5 & 6 & 7 & 8 & 9 & 10 & 11 & 12 & 13 & 14 & 15 & $17 \quad 18$ \\
\hline 1. Could breach ${ }^{\mathrm{a}}$ & - & & & & & & & & & & & & & & \multirow{2}{*}{\multicolumn{2}{|c|}{ Outcome Scores $(Y)$}} \\
\hline 2. Should breach ${ }^{\mathrm{a}}$ & .14 & - & & & & & & & & & & & & & & \\
\hline 3. $\mathrm{PCSO}-\mathrm{C}^{\mathrm{a}}$ & .07 & $-.28^{* *}$ & - & & & & & & & & & & & & & \multirow{3}{*}{ Group $(X)$} \\
\hline 4. $\mathrm{GP}^{\mathrm{a}}$ & -.01 & $-.15^{*}$ & $\mathrm{f}$ & - & & & & & & & & & & & & \\
\hline 5. $\mathrm{UG}^{\mathrm{a}}$ & -.05 & $.38^{* *}$ & $\mathrm{f}$ & $\mathrm{f}$ & - & & & & & & & & & & & \\
\hline 6. Experience ${ }^{a}$ & .14 & $-.27^{* *}$ & $.92^{* *}$ & $-.34^{* *}$ & $-.45^{* *}$ & - & & & & & & & & & & \multirow{3}{*}{ Info Source } \\
\hline 7. News ${ }^{a}$ & -.05 & .12 & $-.24^{* *}$ & $.22^{* *}$ & -.004 & $-.33^{* *}$ & - & & & & & & & & & \\
\hline 8. Social media ${ }^{a}$ & -.13 & $.19^{*}$ & $-.30^{* *}$ & $-.16^{*}$ & $.40^{* *}$ & $-.28^{* *}$ & $-.38^{* *}$ & - & & & & & & & & \\
\hline 9. Education ${ }^{a}$ & .09 & -0.06 & $-.21^{* *}$ & $.18^{*}$ & .01 & $-.22^{* *}$ & $-.31^{* *}$ & $-.26^{* *}$ & - & & & & & & & \\
\hline 10. Attitude ${ }^{b}$ & $-.16^{*}$ & $.41^{* *}$ & $-.59^{* *}$ & .13 & $.37^{* *}$ & $-.55^{* *}$ & $.27^{* *}$ & $.17^{*}$ & -.02 & - & & & & & & \multirow{2}{*}{$\begin{array}{r}\text { Mediator }(M) \& \\
\text { Moderator }(W)\end{array}$} \\
\hline 11. Support ${ }^{\mathrm{c}}$ & -.15 & $.26^{* *}$ & $-.49^{* *}$ & $.21^{* *}$ & $.21^{* *}$ & $-.44^{* *}$ & $.23^{* *}$ & .04 & .10 & $.37^{* *}$ & - & & & & & \\
\hline 12. Age & -.01 & $-.30^{* *}$ & $.71^{* *}$ & .01 & $-.66^{* *}$ & $.67^{* *}$ & -.04 & $-.40^{* *}$ & -.13 & $-.44^{* *}$ & $-.26^{* *}$ & - & & & & \multirow{3}{*}{ Demographics } \\
\hline 13. Gender ${ }^{d}$ & .001 & $.23^{* *}$ & $-.61^{* *}$ & $.23^{* *}$ & $.32^{* *}$ & $-.56^{* *}$ & $.15^{*}$ & .12 & .12 & $.36^{* * *}$ & $.30^{* *}$ & $-.43^{* *}$ & - & & & \\
\hline 14. Forensic exp ${ }^{a}$ & .01 & .02 & $-.24^{* *}$ & .11 & .10 & $-.23^{* *}$ & -.04 & .01 & $.36^{* *}$ & -.04 & $.12^{*}$ & $-.17^{*}$ & $.26^{* *}$ & - & & \\
\hline 15. Parent ${ }^{a}$ & -.06 & $-.16^{*}$ & $.43^{* *}$ & .06 & $-.42^{* *}$ & $.43^{* *}$ & .10 & $-.32^{* *}$ & $-.18^{*}$ & -.13 & -.12 & $.66^{* *}$ & $-.24^{* *}$ & -.13 & - & \\
\hline 16. Political ${ }^{\mathrm{e}}$ & .06 & $-.17^{*}$ & $-.24^{* *}$ & $.22^{* *}$ & -.004 & $-.24^{*}$ & -.07 & .14 & .02 & -.04 & -.03 & $-.13^{*}$ & $.31^{* *}$ & .07 & $-.22^{* *}$ & - \\
\hline 17. Abused ${ }^{a}$ & .11 & $-.20^{*}$ & .15 & .01 & -.13 & .14 & -.09 & -.14 & .09 & $-.20^{*}$ & -.09 & $.14^{*}$ & -.03 & .08 & .13 & .11 \\
\hline 18. Exposure & .08 & $-.18^{*}$ & $.35^{* *}$ & -.09 & $-.21^{* *}$ & $.37^{* *}$ & $-.22^{* *}$ & -.14 & .14 & $-.27^{* *}$ & -.12 & $.27^{* *}$ & $-.16^{*}$ & $.16^{*}$ & $.19^{*}$ & -.06 \\
\hline
\end{tabular}

Note. PCSO-C = people convicted of sexual offences against children. GP = general public. UG $=$ undergraduate students. Experience $=$ having been charged/convicted of sexual offence. Forensic exp $=$ studying, working, or volunteering in forensic area. Abused $=$ history of sexual abuse. Exposure $=$ exposure to information about PCSO. Info source $=$ primary source of information about PCSO.

${ }^{\mathrm{a}} 0=$ no and $1=$ yes. ${ }^{\mathrm{b}}$ higher $=$ more negative. ${ }^{\mathrm{c}}$ higher $=$ more supportive. ${ }^{\mathrm{d}} 0=$ male and $1=$ female.${ }^{\mathrm{e}}$ higher $=$ more liberal. ${ }^{\mathrm{f}}$ Participants could only be in one of the three groups, so these correlations were negative but not meaningful.

${ }^{*} p<.05 .{ }^{* *} p<.01$. 


\section{Appendix D}

Proportion of Each Group Reporting Scenarios Could and/or Should Constitute a Breach
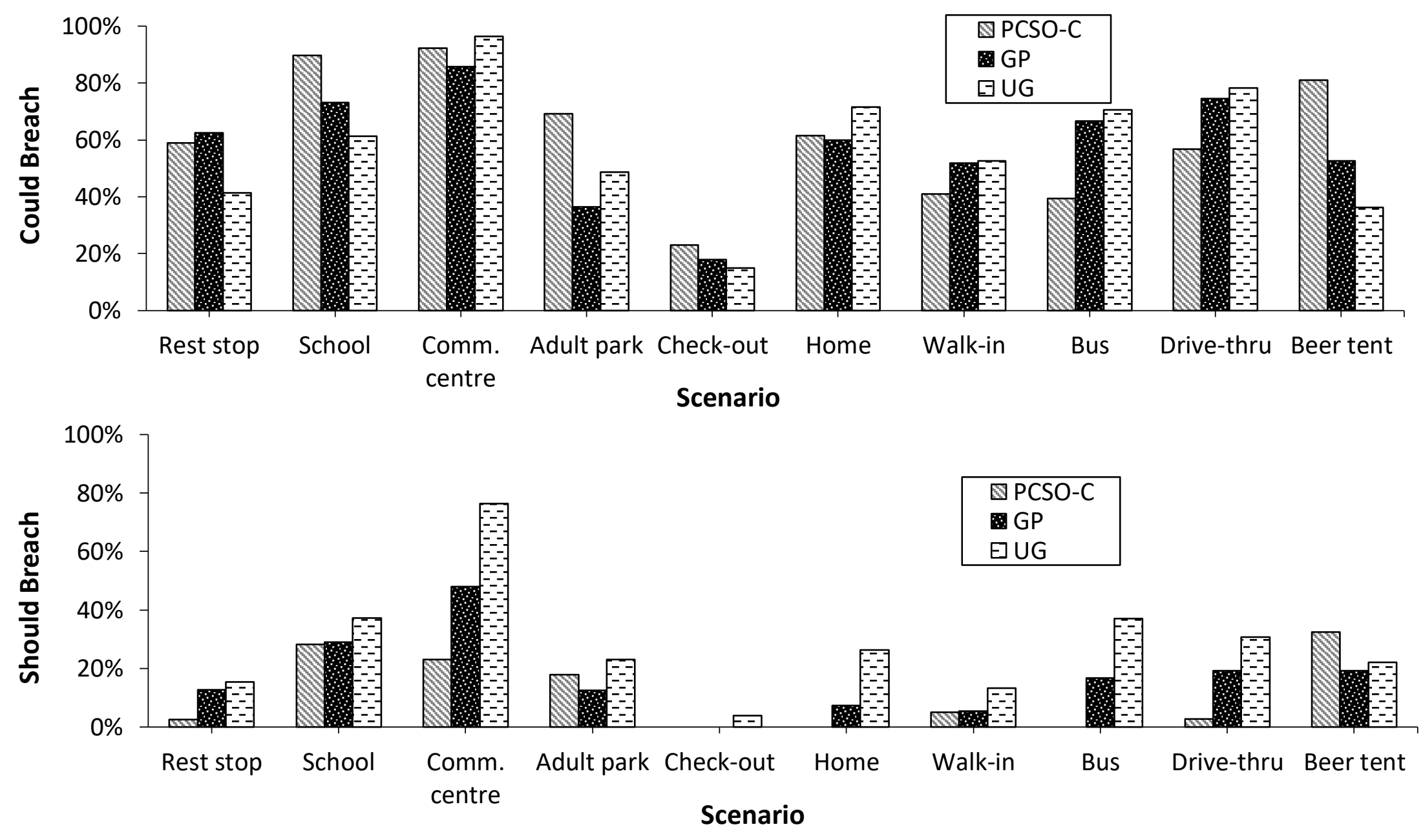
Note. Figures A and B use the same scale for ease of comparison. Differences between bar values and 100 represent the percentage of each group reporting the scenario could not or should not result in a breach. PCSO-C = people convicted of sexual offences against children. GP $=$ general public. $\mathrm{UG}=$ undergraduate students. 


\section{Appendix E}

Regression Coefficients for Moderated Simple Mediation Models

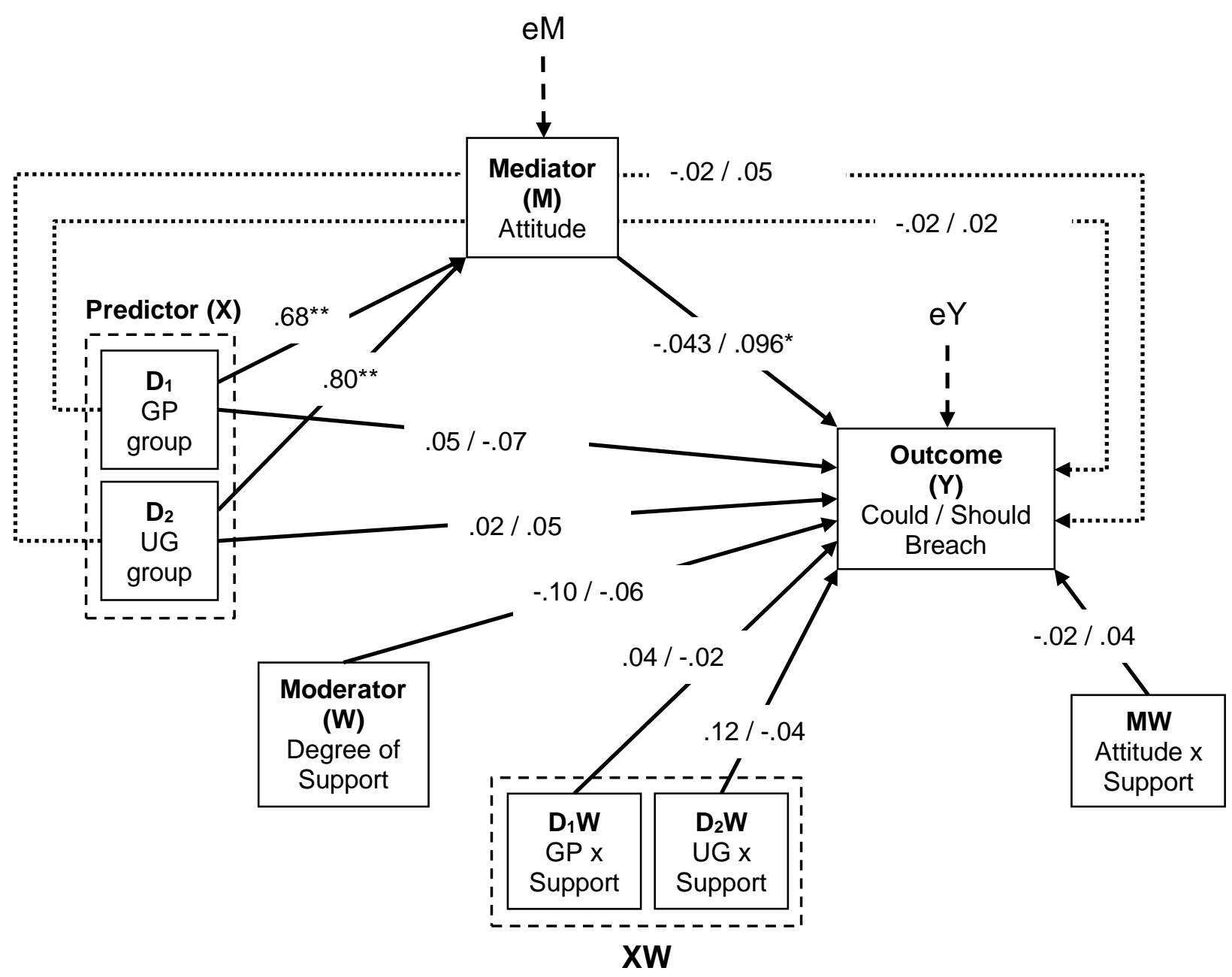

Note. Regression coefficients are unstandardized and controlling for gender. Dotted pathways represent indirect effects. Coefficients are for Could Breach model / Should Breach model. GP = general public. $\mathrm{UG}=$ undergraduate students. $\mathrm{eM}$ and $\mathrm{eY}$ represent error terms for the mediator and outcome variables, respectively.

${ }^{*} p<.01,{ }^{* *} p<.001$ 


\section{Appendix F}

Chi-square Results for Comparison of Study Groups

\begin{tabular}{ccccccc}
\hline PCSO-C & GP & UG & $X^{2}$ & $p$ & $V$ \\
\hline$\%$ within group & & & \\
\hline
\end{tabular}

Gender

Males

$100 \mathrm{a} \quad 29.6 \mathrm{~b} \quad 18.8 \mathrm{~b}$

Females

$0.0 \mathrm{a} \quad 70.4 \mathrm{~b} \quad 81.3 \mathrm{~b}$

$75.7<.001$

.66

Ethnicity

Caucasian

Non-Caucasian

$100 \mathrm{a} \quad 80.4 \mathrm{~b} \quad 59.5 \mathrm{c}$

$0.0 \mathrm{a} \quad 19.6 \mathrm{~b} \quad 40.5 \mathrm{c}$

$24.7<.001$

Education

High school

$40.6 \mathrm{a} \quad 24.1_{\mathrm{a}} \quad 78.5 \mathrm{~b}$

College

$34.4 \mathrm{a}$

$11.1_{\mathrm{b}}$

$17.7_{\mathrm{a}, \mathrm{b}}$

$67.8<.001$

.45

University

$\begin{array}{lll}25 \mathrm{a} & 64.8 \mathrm{~b} & 3.8 \mathrm{c}\end{array}$

Marital status

Not married

$38.5 \mathrm{a} \quad 48.2 \mathrm{a} \quad 93.8 \mathrm{~b}$

Married/common-law

28.2

$50.0_{a}$

$5.0 \mathrm{~b}$

$79.6<.001$

.48

Separated/divorced

$33.3 \mathrm{a}$

$1.8 \mathrm{~b}$

$1.3 \mathrm{~b}$

Employment

Employed

Unemployed

Other

Political views

Conservative

Liberal

Other/neither $56.4_{\mathrm{a}, \mathrm{b}} \quad 74.1 \mathrm{~b} \quad 46.3_{\mathrm{a}}$

$23.1_{a} \quad 11.1_{a, b} \quad 7.5 \mathrm{~b}$

$20.5 \mathrm{a} \quad 14.8 \mathrm{a} \quad 46.3 \mathrm{~b}$
$21.8<.001$

$25.6 \mathrm{a} \quad 18.2 \mathrm{a} \quad 11.3 \mathrm{a}$

$30.8 \mathrm{a} \quad 65.5 \mathrm{~b} \quad 49.3_{\mathrm{a}, \mathrm{b}}$

$43.6 \mathrm{a} \quad 16.4 \mathrm{~b} \quad 39.4 \mathrm{a}$

Primary source of information about sexual offending

$\begin{array}{llll}\text { Personal experience }^{\mathrm{a}} & 87.2 \mathrm{a} & 0.0 \mathrm{~b} & 0.0 \mathrm{~b}\end{array}$

News

$10.3 \mathrm{a} \quad 46.4 \mathrm{~b} \quad 31.3 \mathrm{~b}$

$163.6<.001$

.68

Social media

$0.0 \mathrm{a} \quad 14.3 \mathrm{~b} \quad 42.5 \mathrm{c}$ 


\begin{tabular}{lcccccc}
\hline & PCSO-C & GP & UG & $X^{2}$ & $p$ & $V$ \\
\cline { 2 - 7 } & \multicolumn{7}{c}{$\%$ within group } & & & \\
\hline \multicolumn{1}{c}{ Education/training } & $2.6_{\mathrm{a}}$ & $26.8 \mathrm{~b}$ & $17.5 \mathrm{a}, \mathrm{b}$ & & & \\
$\quad$ Other & $0.0_{\mathrm{a}}$ & $12.5_{\mathrm{a}}$ & $8.8_{\mathrm{a}}$ & & & \\
Has children (Y) & $64.1_{\mathrm{a}}$ & $32.1_{\mathrm{b}}$ & $7.6_{\mathrm{c}}$ & 41.9 & $<.001$ & .49 \\
Hx of sexual abuse (Y) & $41.0_{\mathrm{a}}$ & $29.4_{\mathrm{a}}$ & $22.4_{\mathrm{a}}$ & 4.4 & .112 & .16 \\
Forensic experience $^{\mathrm{b}}(\mathrm{Y})$ & $10.3 \mathrm{a}$ & $37.5 \mathrm{~b}$ & $35.4 \mathrm{~b}$ & 9.8 & .008 & .24 \\
\hline
\end{tabular}

Note. Different subscript letters represent differences in column proportions that are significant at $p<.05$. PCSO-C $=$ people convicted of sexual offences against children. $\mathrm{GP}=$ general public. $\mathrm{UG}=$ undergraduate students. Those without a HS diploma were excluded due to low cell counts in the GP and UG groups.

${ }^{a}$ Refers to having been charged/convicted of a sexual offence. ${ }^{b}$ Refers to working, studying, or volunteering in forensic area. 